Portland State University

PDXScholar

9-19-1997

\title{
Human Trampling in the Upper Rocky Intertidal: Trampling and Recovery in Barnacle Mediated Succession
}

Timothy Lawrence Grubba Portland State University

Follow this and additional works at: https://pdxscholar.library.pdx.edu/open_access_etds

Part of the Biology Commons, Population Biology Commons, and the Terrestrial and Aquatic Ecology Commons

Let us know how access to this document benefits you.

\section{Recommended Citation}

Grubba, Timothy Lawrence, "Human Trampling in the Upper Rocky Intertidal: Trampling and Recovery in Barnacle Mediated Succession" (1997). Dissertations and Theses. Paper 5373.

https://doi.org/10.15760/etd.7246

This Thesis is brought to you for free and open access. It has been accepted for inclusion in Dissertations and Theses by an authorized administrator of PDXScholar. Please contact us if we can make this document more accessible: pdxscholar@pdx.edu. 
The abstract and thesis of Timothy Lawrence Grubba for the Master of

Science in Biology were presented June 2, 1997, and accepted by the thesis committee and the department.

COMMITTEE APPROVALS:
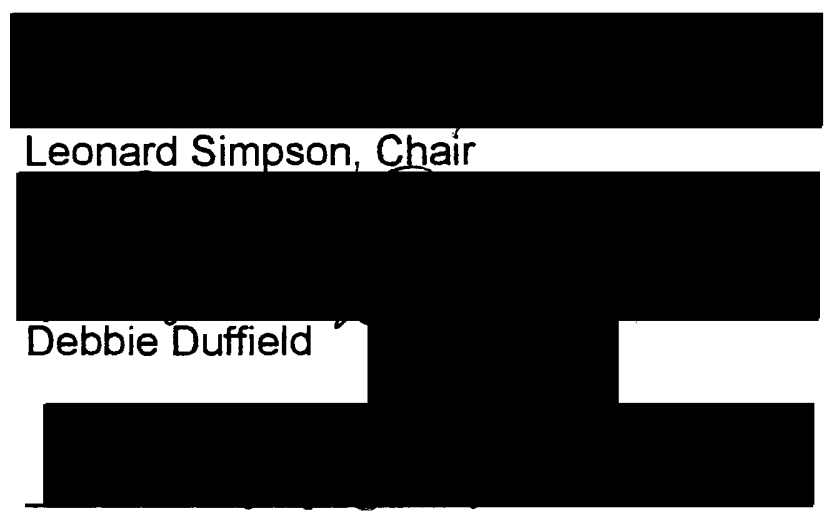

Richard Forbes

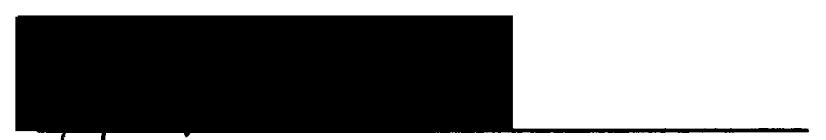

Jarhes Pratt

Representative of the Office of Graduate Studies

DEPARTMENT APPROVAL:

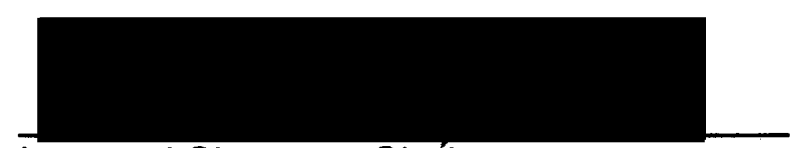

Leonard Simpson, Chair

Department of Biology

ACCEPTED FOR PORTLAND STATE UNIVERSITY BY THE LIBRARY

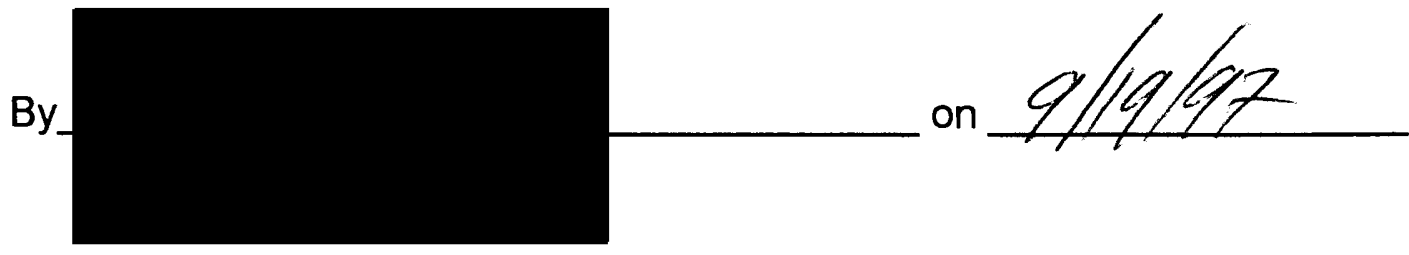




\section{ABSTRACT}

An Abstract of the thesis of Timothy Lawrence Grubba for the Master of Science in Biology presented June 2, 1997.

Title: Human Trampling in the Upper Rocky Intertidal: Trampling and recovery in barnacle mediated succession.

Marine intertidal ecosystems are vulnerable to human interference, because trampling can be a significant problem. I studied the impacts of trampling on community patterns and succession in a rocky intertidal habitats. This study was divided into two phases: (1) a trampling phase and (2) a recovery phase. Both phases are focused on two barnacles, Balanus glandula and Chthamalus dalli, and on fucoid and red algae. The trampling phase tested the effects of trampling on these organisms. The effects of herbivores, primarily limpets (Collisella digitalis) were also tested to determine whether anthropogenic (trampling) and natural (herbivory and limpet bulldozing) disturbances had independent or additive effects. The recovery phase monitored the recovery of these species after trampling was stopped.

A randomized block design was set up at two sites on the Oregon coast. Light and heavy trampling regimes and herbivore inclusion and 
exclusion treatments were applied, to permit comparisons with control plots. During the trampling phase, experimental plots were trampled monthly from November 1992 to July 1993. During the recovery phase, the experimental plots were not trampled and recovery was monitored from August 1993 to October 1994.

Trampling severely reduced the abundance of $\underline{B}$. glandula, but the smaller $\underline{\mathrm{C}}$ dalli increased. This increased abundance was due both to resistance of $\underline{\mathbf{C}}$. dalli to trampling and to reduced competition from $\underline{B}$. glandula. Herbivores reduced abundance of newly-settled $\underline{\text { B }}$ glandula , but had no effect on $\underline{\mathrm{C}}$. dalli. Cover of algae declined rapidly under trampling. This was due both to direct effects and to removal of $\underline{B}$. glandula, the settlement substrate. Trampling had severe effects on overall community composition. Some species were eliminated, and succession was prevented. In this study, light and heavy trampling had equally detrimental effects. Trampling swamped potential herbivore effects.

Recovery/succession after trampling was slow as $\underline{B}$. glandula, a facilitative species was in low abundance. Chthamalus dalli abundance was high due to high recruitment and to release from competition. Chthamalus dalli individuals grew to unusually large sizes, which enabled them to function as a facilitative species. This occurrence enabled succession to proceed despite the absence of $\underline{B}$. glandula. Because it has already established, $\underline{C}$. dalli in this large form has a short term competitive 
dominance over $\underline{B}$. glandula. With increased recruitment of $\underline{B}$. glandula, over time, the pre-emptive competition will fail and $\underline{B}$. glandula regain dominance. 
HUMAN TRAMPLING IN THE UPPER ROCKY INTERTIDAL: TRAMPLING AND RECOVERY IN BARNACLE MEDIATED SUCCESSION

\title{
BY
}

TIMOTHY LAWRENCE GRUBBA

A thesis submitted in partial fulfillment of the

requirements for the degree of

\author{
MASTER OF SCIENCE \\ in \\ BIOLOGY
}

Portland State University

1997 
Table of Contents

\begin{tabular}{ll} 
& Page \\
\hline List of tables & $\mathrm{iii}$ \\
List of figures & $\mathrm{v}$ \\
Introduction & $\mathbf{1}$ \\
The Barnacle-Algal Assemblage & 6 \\
Effects of trampling and herbivores on marine communities: & 9 \\
Predictions &
\end{tabular}

Study Area

Methods

Data Analysis

Results

Trampling Phase

Barnacles

Balanus glandula

Chthamalus dalli

Fucoid Algae

Canopy Cover

Primary Cover 33

Endocladia muricata

Recovery Phase

Barnacles

Balanus glandula 
Fucoid Algae

Canopy Cover 50

Primary Cover $\quad 55$

Endocladia muricata $\quad 58$

Discussion $\quad 61$

Trampling Intensity 63

Interactions between trampling and herbivore effects 65

Effects of trampling on barnacles 66

Effects of trampling on algae $\quad 67$

Spatial heterogeneity $\quad 68$

Effects of trampling on successional pathway 69

$\begin{array}{ll}\text { Conclusions } & 71\end{array}$

$\begin{array}{ll}\text { References } & 72\end{array}$ 


\section{List of Tables}

Table

Page

$1 . \quad$ Predicted outcomes of trampling

2. Predicted recovery pathway 11

3. Summary of RMANOVA on abundance of barnacles 22

(Balanus glandula) in the trampling phase. Data were arcsine-transformed prior to analysis

4. Summary of RMANOVA on abundance of barnacles 27

(Chthamalus dalli) in the trampling phase. Data were arcsine-transformed prior to analysis

5. Summary of RMANOVA on abundance of Fucoid algae (Canopy) in the trampling phase. Data were arcsinetransformed prior to analysis

6. Summary of RMANOVA on abundance of Fucoid algae 36 (Primary) in the trampling phase. Data were arcsinetransformed prior to analysis

7. Summary of RMANOVA on abundance of Endocladia 39 muricata in the trampling phase. Data were arcsinetransformed prior to analysis

8. Summary of RMANOVA on abundance of Balanus glandula in the recovery phase. Data were arcsinetransformed prior to analysis

9. Summary of RMANOVA on abundance of Chthamalus 49 dalli in the recovery phase. Data were arcsinetransformed prior to analysis

10. Summary of RMANOVA on abundance of Fucoid algae 54 (Canopy) in the recovery phase. Data were arcsinetransformed prior to analysis 
11. Summary of RMANOVA on abundance of Endocladia 60 muricata in the recovery phase. Data were arcsinetransformed prior to analysis

12. Predictions/Results during the trampling phase 62

13. Predictions/Results during recovery phase 63 


\section{List of Figures}

Figure

Page

$1 . \quad$ The position of the upper intertidal zone

2. Main species interactions in the upper intertidal zone 8

3. The layout of trampling and herbivore treatment 14 combinations in one block

4. Effect of trampling on Balanus glandula at Fogarty 20 Creek in the presence and absence of herbivores. Data points represent the mean, and vertical bars are \pm 1 SE.

5. Effect of trampling on Balanus glandula at Yaquina 21 Head in the presence and absence of herbivores. Data points represent the mean, and vertical bars are \pm 1 SE.

6. Effect of trampling on Chthamalus dalli at Fogarty 25 Creek in the presence and absence of herbivores. Data points represent the mean, and vertical bars are \pm 1 SE.

7. Effect of trampling on Chthamalus dalli at Yaquina 26 Head in the presence and absence of herbivores. Data points represent the mean, and vertical bars are \pm 1 SE.

8. Effect of trampling on Fucoid algae (Canopy) at 30 Fogarty Creek in the presence and absence of herbivores. Data points represent the mean, and vertical bars are $\pm 1 \mathrm{SE}$.

9. Effect of trampling on Fucoid algae (Canopy) at Yaquina Head in the presence and absence of herbivores. Data points represent the mean, and 
vertical bars are $\pm 1 \mathrm{SE}$.

10. Effect of trampling on Fucoid algae (Primary) at

Fogarty Creek in the presence and absence of

herbivores. Data points represent the mean, and vertical bars are $\pm 1 \mathrm{SE}$.

11. Effect of trampling on Fucoid algae (Primary) at Yaquina Head in the presence and absence of herbivores. Data points represent the mean, and vertical bars are $\pm 1 \mathrm{SE}$.

12. Effect of trampling on Endocladia muricata at Fogarty Creek in the presence and absence of herbivores. Data points represent the mean, and vertical bars are \pm 1 SE.

13. Recovery of Balanus glandula at Fogarty Creek in the presence and absence of herbivores. Data points represent the mean, and vertical bars are \pm 1 SE.

14. Recovery of Balanus glandula at Yaquina Head in the presence and absence of herbivores. Data points represent the mean, and vertical bars are $\pm 1 \mathrm{SE}$.

15. Recovery of Chthamalus dalli at Fogarty Creek in the presence and absence of herbivores. Data points represent the mean, and vertical bars are $\pm 1 \mathrm{SE}$.

16. Recovery of Chthamalus dalli at Yaquina Head in the presence and absence of herbivores. Data points represent the mean, and vertical bars are $\pm 1 \mathrm{SE}$.

17. Recovery of Fucoid algae (Canopy) at Fogarty Creek in 52 the presence and absence of herbivores. Data points represent the mean, and vertical bars are $\pm 1 \mathrm{SE}$. 
18. Recovery of Fucoid algae (Canopy) at Yaquina Head in 53 the presence and absence of herbivores. Data points represent the mean, and vertical bars are $\pm 1 \mathrm{SE}$.

19. Recovery of Fucoid algae (Primary) at Fogarty Creek in 56 the presence and absence of herbivores. Data points represent the mean, and vertical bars are $\pm 1 \mathrm{SE}$.

20. Recovery of Fucoid algae (Primary) at Yaquina Head in 57 the presence and absence of herbivores. Data points represent the mean, and vertical bars are $\pm 1 \mathrm{SE}$.

21. Recovery of Endocladia muricata at Fogarty Creek in 59 the presence and absence of herbivores. Data points represent the mean, and vertical bars are $\pm 1 \mathrm{SE}$. 


\section{INTRODUCTION}

Human use of rocky intertidal areas alters the abundance of species, and also affects key processes and interactions in the communities (e.g., Castilla \& Duran 1985, Olvia \& Castilla 1986, Ortega 1987, Castilla \& Bustamente 1989, Duran \& Castilla 1989, Godoy \& Moreno 1989, Keough \& Quinn 1992, Osenberg \& Schmitt 1994, Osenberg et al. 1994, Thrush et al. 1994). The effects of species reduction or removal by harvesting on community dynamics have been the focus of much attention (e.g., Moreno et al. 1984, Castilla \& Duran 1985, Hockey \& Bosman 1986, Olvia \& Castilla 1986, Ortega 1987, Castilla \& Bustamente 1989, Duran \& Castilla 1989, Godoy \& Moreno 1989, Underwood \& Kennelly 1990). Human trampling is also known to affect community structure in many marine communities, including rocky intertidal shores (Zedler 1976, 1978, Beauchamp \& Gowing 1982, Ghazanshahi et al. 1983, Castilla \& Bustamente 1989, Povey \& Keough 1991, Brosnan \& Crumrine 1992a, 1994, Brosnan 1993, Elliott 1996) and coral reef flats (Liddle 1975, 1991, Liddle \& Kay 1987, Kay \& Liddle 1989). The impact of trampling on intertidal communities is likely to increase as more people visit the shore for educational, scientific and recreational use. 
The effects of trampling on terrestrial communities have been much studied. (e.g., Jeffreys 1917, Shantz 1917, Bates 1934, 1935, Sun and Liddle 1993). Trampling also alters plant communities in alpine meadows, forests and sand dunes (Burden and Randerson 1972, Liddle 1975, Hylgaard and Liddle 1981, Nickerson and Thibodeau 1983, Sun and Liddle 1993). Certain species are susceptible to trampling, while others thrive in trampled areas (Sun and Liddle 1993). Trampling impacts on marine communities have, until recently, received less attention. In the 1970's, repeated surveys of marine areas showed that communities changed, as human population density and shore access increased (Widdowson 1971, Boalche et al. 1974, Thom and Widdowson 1978). Recently there have been more direct observational and comparative studies (Zedler 1976, 1978, Beauchamp and Gowing 1982, Ghazanshahi et al. 1983), and experimental studies on the effects of trampling on intertidal communities (e.g., Castilla and Bustamente 1989, Povey and Keough 1991, Brosnan and Crumrine 1992a, 1994, Brosnan 1993). Studies show that trampling has predictable effects on community patterns. Fucoid algae are particularly susceptible to trampling and are often rare at heavily visited sites (Zedler 1976, 1978, Beauchamp and Gowing 1982, Ghazanshahi et al. 1983, Povey and Keough 1991, Brosnan and Crumine 1992a, b, 1994, Brosnan 1993). Low-growing algal turf are more resistant to dislodgment (Povey and Keough 1991, 
Brosnan and Crumrine 1992a, b, 1994, Brosnan 1993, Elliott et al. unpublished manuscript). These studies establish the sometimes dramatic effects of trampling on competitive dominants and on later successional species. In this study, l extend the investigation of the effects of trampling to other organisms and its effects on successional pathways.

Most of the above experimental studies considered only a few groups, mainly algae (Povey and Keough 1991, Brosnan and Crumrine 1992a, b, 1994), and gastropods (Povey and Keough 1991) in high and midintertidal zones, and mussels in the mid intertidal zone (Brosnan and Crumrine 1992a, 1994). Few studies have focused on the direct effects of trampling on barnacles or on indirect effects on the community brought about by effects on the barnacles. Barnacles dominate or form mixed algalbarnacle assemblages in the upper intertidal zone of many temperate rocky shores (Lewis 1964, Connell 1961, Stephenson and Stephenson 1972). Barnacles often play a key role in succession, by facilitating the establishment of other species (e.g., Hawkins 1981, Hawkins and Hartnoll 1983, Lubchenco 1978, 1983, Hartnoll and Hawkins 1985, Navarette and Castilla 1990, Farrell 1991). Brosnan and Crumrine (1994) noted that barnacle abundance were reduced by trampling. However, they did not distinguish between barnacle species, or consider the indirect impacts of this on the community. In addition, no study that I am aware of, has 
examined at interactions between the effects of trampling and biotic disturbance, e.g. bulldozing effects of herbivores. If trampling and natural disturbances have additive effects, this may magnify the importance of human disturbance. In this study, I experimentally tested the effects of trampling intensity on species composition and abundance of barnacles, and algal species associated with barnacles. I also experimentally tested interactions between trampling and herbivores (Limpets, Collisella digitalis), and how they affect barnacles and algae.

Barnacles are often an essential link in the successional process (e.g., Hawkins 1981, 1983, Hawkins and Hartnoll 1983, Hartnoll and Hawkins 1985, Farrell 1989, 1991). Their tests provide a settlement site for algae and mussels. Recruitment of algae and mussels is often higher onto barnacle tests than onto bare rock (e.g., Burrows and Lodge 1950, Lubchenco 1978, 1983, Hawkins 1981, 1983, Petersen 1984a, b, Hartnoll and Hawkins 1985, Farrell 1989, 1991, Navarette and Castilla 1990). In studies on the Oregon coast, Farrell (1991) found that algal colonization and succession were dependent on barnacles. Brosnan (unpublished manuscript) confirmed that algae do not become established in the absence of barnacles. Similarly, Lubchenco (1983) found that barnacles were nearly essential for the establishment of algae on shores in New England. On rocky shores in England, the presence of barnacles plays a key role in determining 
the rate and trajectory of succession (Hawkins and Hartnoll 1983, Hartnoll and Hawkins 1985). Previous studies have shown that human trampling leads to reductions in abundance and diversity of barnacles and algae (e.g., Povey and Keough 1991, Brosnan and Crumrine 1992a, 1994). However, trampling effects on algae may be either by direct removal or by indirect removal of settlement substrate (barnacles). Thus by removing barnacles, trampling may also prevent algal recovery.

Abundance of barnacles and algae is also affected by herbivores. Limpets, for example remove barnacles by bulldozing them (Branch 1975, 1981). Thus, trampling and herbivory may have additive effects on barnacle abundance. Herbivores also reduce algal abundance directly (e.g., Branch 1975, 1981, Lubchenco 1978, 1983, 1985, Underwood 1980, Jernakoff 1983, Cubit 1984, Sousa 1984) and thus may retard succession (Farrell $1989,1991)$. Again, the effects of trampling and herbivory may be additive; we may also expect both direct effects on algae, and indirect effects exerted through effects on barnacles. 


\section{The Barnacle-Algal Assemblage}

Experiments were carried out in the upper intertidal zone on shores of the Oregon, USA (Fig 1). Two species of barnacles co-exist in this zone, Balanus glandula and Chthamalus dalli (Kozloff 1973). Balanus glandula is the larger species and outcompetes $\underline{\underline{C}}$. dalli for space (Farrell 1989, 1991). Algal recruitment is largely dependent on facilitation by $\underline{B}$. glandula (Farrell 1991, Brosnan unpublished manuscript). Facilitation by $\underline{C}$. dalli is relatively unimportant (Farrell 1991). Limpets, as they graze on algae significantly reduce the abundance of $\underline{\text { B. }}$ glandula by bulldozing them (Farrell 1989,

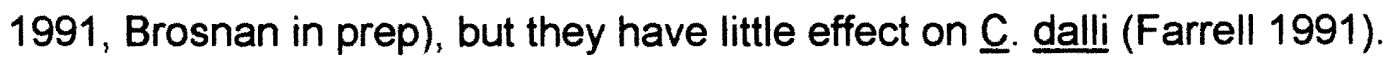
Thus, Coexistence of these barnacle species is, therefore partly facilitated by limpets (Farrell 1989). Figure 2, summarizes the main interactions that occur in the upper intertidal zone.

The upper intertidal zone is dominated by barnacles, or by a mixed assemblage of barnacles and algae. Algae often establish on barnacles, and spread to primary substrate (Farrell 1991, Brosnan personal observation).

The main algal species on this part of the shore are fucoids (Pelvetiopsis limitata, Fucus distichus), red algae (Mastocarpus papillatus, Iridaea cornucopiae, Endocladia muricata, and Petrocelis, the tetrasporic crust phase of $\underline{M}$. papillatus,), and the green alga Ulva sp. is occasionally common. 


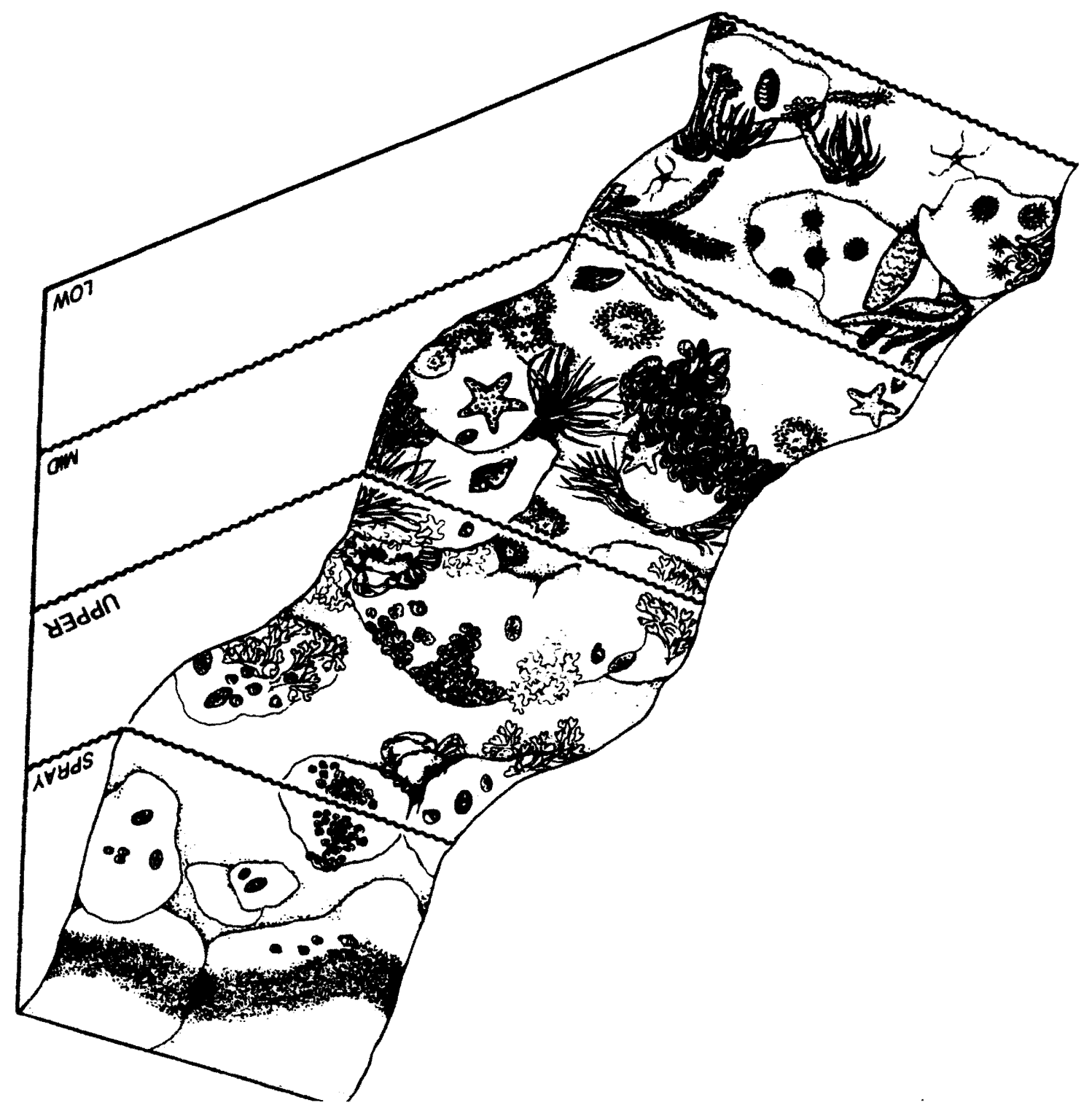

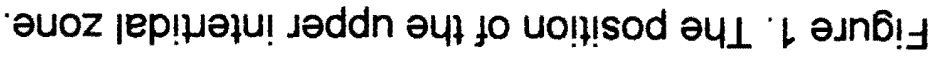


Figure 2. Main species interactions in the upper intertidal zone

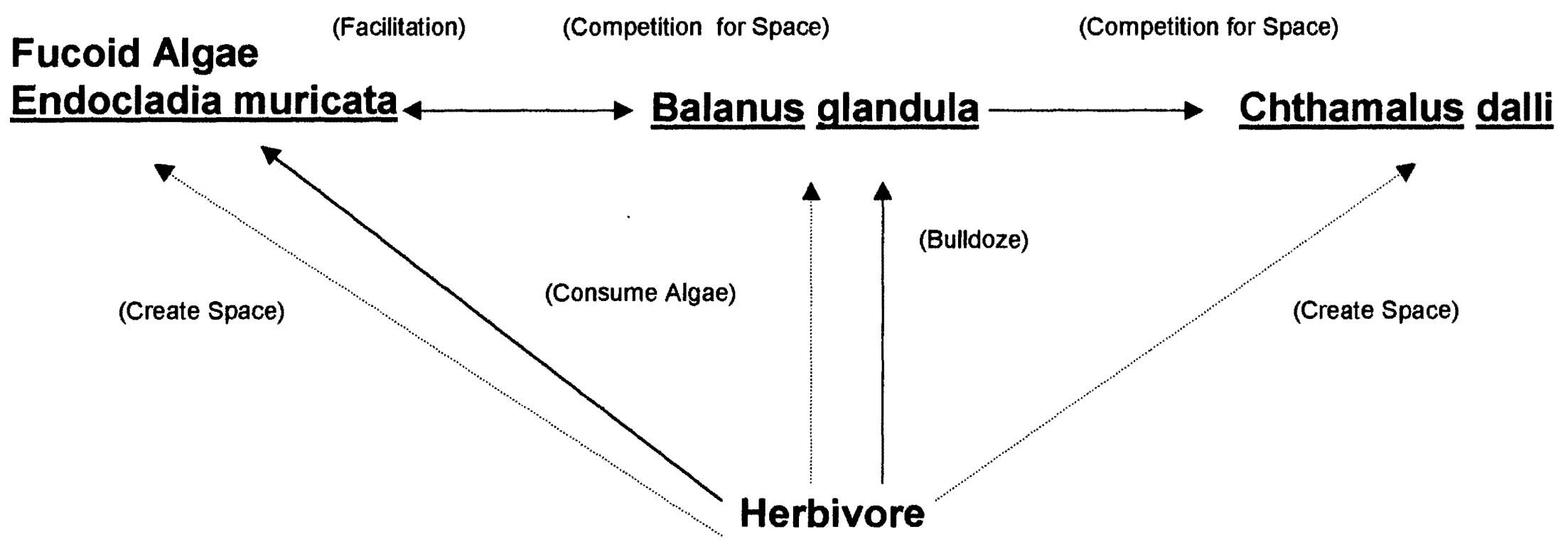


Effects of Trampling and Herbivores on marine communities:

\section{Predictions}

Trampling removes biomass and creates space (Brosnan and Crumrine 1994). If trampling removes key species in a community then community wide processes, including species colonization and abundance will be affected. Table 1 summarizes predictions in the trampling phase for changes in species abundance and composition under light and heavy trampling intensities, and in the presence or absence of herbivores. Table 2 summarizes predictions for the recovery phase. The predictions in Table 2 are based on no significant herbivore effects and no significant differences between trampling intensities. 
Table1. Predicted outcomes of trampling.

\begin{tabular}{|c|c|c|}
\hline & HERBIVORES PRESENT & HERBIVORS EXCLUDED \\
\hline $\begin{array}{l}\text { NO TRAMPLING } \\
\text { (CONTROL) }\end{array}$ & $\begin{array}{l}\text { B. glandula will be the } \\
\text { dominant barnacle: Percent } \\
\text { cover of } \underline{\text { C. dalli will be low. }} \\
\text { Late successional algae (e.g., } \\
\text { fucoids) will be common and } \\
\text { many species will be } \\
\text { associated with barnacles. } \\
\text { Early successional species } \\
\text { will be rare. Herbivore- } \\
\text { resistant species will be } \\
\text { present. }\end{array}$ & $\begin{array}{l}\text { B. glandula will outcompete, } \\
\text { and exclude } \underline{\mathrm{C}} \text {. dalli. Algae } \\
\text { will be more abundant than in } \\
\text { herbivore inclusion areas. } \\
\text { Algae may overgrow and } \\
\text { smother barnacles. }\end{array}$ \\
\hline $\begin{array}{l}\text { LIGHT } \\
\text { TRAMPLING }\end{array}$ & $\begin{array}{l}\text { There will be some reduction } \\
\text { in biomass but no large } \\
\text { changes in community } \\
\text { composition. } \underline{B} \text {. glandula will } \\
\text { show some reduction from } \\
\text { trampling and grazers, and } \\
\text { this will lead to increased } \\
\text { abundance of } \underline{\text { C. dalli. Algal }} \\
\text { turf and grazer-resistant } \\
\text { species will be common. } \\
\text { Algal canopy will be present, } \\
\text { but reduced from non- } \\
\text { trampled control levels. }\end{array}$ & $\begin{array}{l}\text { B. glandula and foliose algae } \\
\text { will be more abundant than in } \\
\text { light trampling and the } \\
\text { presence of grazers, and } \underline{C} \text {. } \\
\text { dalli will be less abundant. } \\
\text { Herbivore-resistant algae will } \\
\text { be uncommon. Algal canopy } \\
\text { will be less abundant than in } \\
\text { control areas, but will still be } \\
\text { relatively common. Overall, I } \\
\text { predict a reduction in the } \\
\text { abundance of certain species } \\
\text { under light trampling } \\
\text { conditions, but I do not } \\
\text { predict that these species will } \\
\text { be reduced to near zero } \\
\text { levels. }\end{array}$ \\
\hline $\begin{array}{l}\text { HEAVY } \\
\text { TRAMPLING }\end{array}$ & $\begin{array}{l}\text { B. glandula cover will be } \\
\text { significantly reduced. } \\
\text { Because it is smaller, } \underline{\mathrm{C}} \text {. dalli } \\
\text { is less likely to be affected by } \\
\text { trampling, and will be the } \\
\text { most abundant barnacle } \\
\text { species. Cover of fucoid } \\
\text { algae will decrease } \\
\text { dramatically. Cover will } \\
\text { remain low, because B. } \\
\text { glandula substrate will be } \\
\text { unavailable. Algal turf and } \\
\text { crusts which are resistant to } \\
\text { trampling and herbivory will } \\
\text { be abundant. The substrate } \\
\text { will be dominated by } \underline{\mathrm{C}} \text {. dalli } \\
\text { and algal turfs and crusts. }\end{array}$ & $\begin{array}{l}\text { A low abundance of } \underline{B} \text {. } \\
\text { glandula, and foliose algae. } \\
\text { Because the detrimental } \\
\text { effects of trampling may be } \\
\text { offset by the absence of } \\
\text { herbivores. Small barnacles } \\
\text { and algae may become } \\
\text { established. Chthamalus dalli } \\
\text { will be common and will co- } \\
\text { exist with } \mathrm{B} \text {. glandula. Under } \\
\text { these conditions species that } \\
\text { dominate in no-trampling } \\
\text { conditions will persist: } \\
\text { However, they will be } \\
\text { significantly less common } \\
\text { and subject to frequent } \\
\text { disturbances from trampling. }\end{array}$ \\
\hline
\end{tabular}


Table 2. Predicted recovery pathway.

\begin{tabular}{|l|l|}
\hline & HERBIVORES PRESENT AND EXCLUSION \\
\hline $\begin{array}{l}\text { No TRAMPLING } \\
\text { (CONTROL) }\end{array}$ & $\begin{array}{l}\text { B. glandula will be the dominant barnacle: Percent cover of } C \text {. } \\
\text { dalli will be low. Late successional algae (e.g., fucoids) will be } \\
\text { common and many species will be associated with barnacles. } \\
\text { Early successional species will be rare. }\end{array}$ \\
\hline $\begin{array}{l}\text { LIGHT } \\
\text { TRAMPLING } \\
\text { AND HEAVY } \\
\text { TRAMPLING }\end{array}$ & $\begin{array}{l}\text { B. glandula abundance will be low while cover of } \mathrm{C} \text {. dalli will } \\
\text { be significantly greater initially. Over time, } B \text {. glandula } \\
\text { abundance increases while } \mathrm{C} \text {. dalli abundance decreases. } \\
\text { The low abundance of } B \text {. glandula will retard establishment of } \\
\text { late successional species such foliose algae. }\end{array}$ \\
\hline
\end{tabular}




\section{STUDY AREA}

Experiments were set up on two rarely visited sites on the central Oregon coast USA, Fogarty Creek $\left(44.51^{\circ} \mathrm{N}: 124.03^{\circ} \mathrm{W}\right)$ and the south headland at Yaquina Head (44.410 N: $124.04 \mathrm{OW})$. Plots were located in the high intertidal zone (1.5-2.0 $\mathrm{m}$ above mean lower low water). These sites were chosen so that trampling from others would not confound the study.

The Yaquina Head site is located at the base of a relatively inaccessible cliff. The area is frequented only by a few local fishermen. Their impact is restricted to small patches, which were not included in the experimental site. The shore consists of a narrow basalt platform and is exposed to a low to medium wave intensity from the southwest. The community at Yaquina Head is dominated by barnacles (Balanus glandula

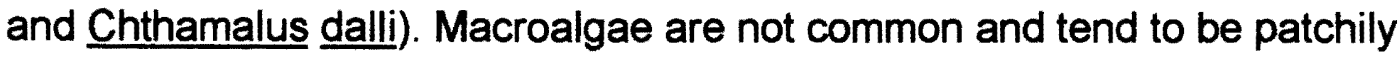
distributed.

The Fogarty Creek site is a basaltic headland which has extensive intertidal benches. Access to the shore is through private property. Apart from other researchers, visitors to the headland are rare. Experiments were set up on a small isolated northern headland. The community in this part of Fogarty Creek is composed of a mixed barnacle-algal assemblage. 
Barnacles (B. glandula and $\underline{\mathrm{C}}$. dalli) are less common at Fogarty Creek than at Yaquina Head. Algal species are more abundant at Fogarty Creek. The main species present include fucoids, mainly Pelvetiopsis limitata and Fucus. distichus, and the red algae (Iridaea cornucopiae, Endocladia muricata, and Mastocarpus papillatus).

\section{METHODS}

The study was divided into a trampling phase and a recovery phase. In both phases a randomized block design was used to test the effects of trampling, and herbivores on the marine community and on the successional pathway. The experimental design consisted of three trampling intensities, (light trampling, heavy trampling, and a non-trampled control treatment), and three herbivore treatments (herbivore exclusion, herbivore inclusion, and a copper-paint control treatment). In each block, one replicate of each of the nine possible combinations of trampling intensity and herbivore treatments was established (Fig 3). There were four blocks at each of the two sites making a total of 72 experimental plots. Plots measured $10 \mathrm{~cm}$ by $10 \mathrm{~cm}$ and were marked out at each corner with a marine epoxy (Z-spar).

During the trampling phase the control plots were not trampled. Trampled plots were trampled monthly for nine months from November 
Figure 3. The layout of trampling and herbivore treatment combinations in one block..

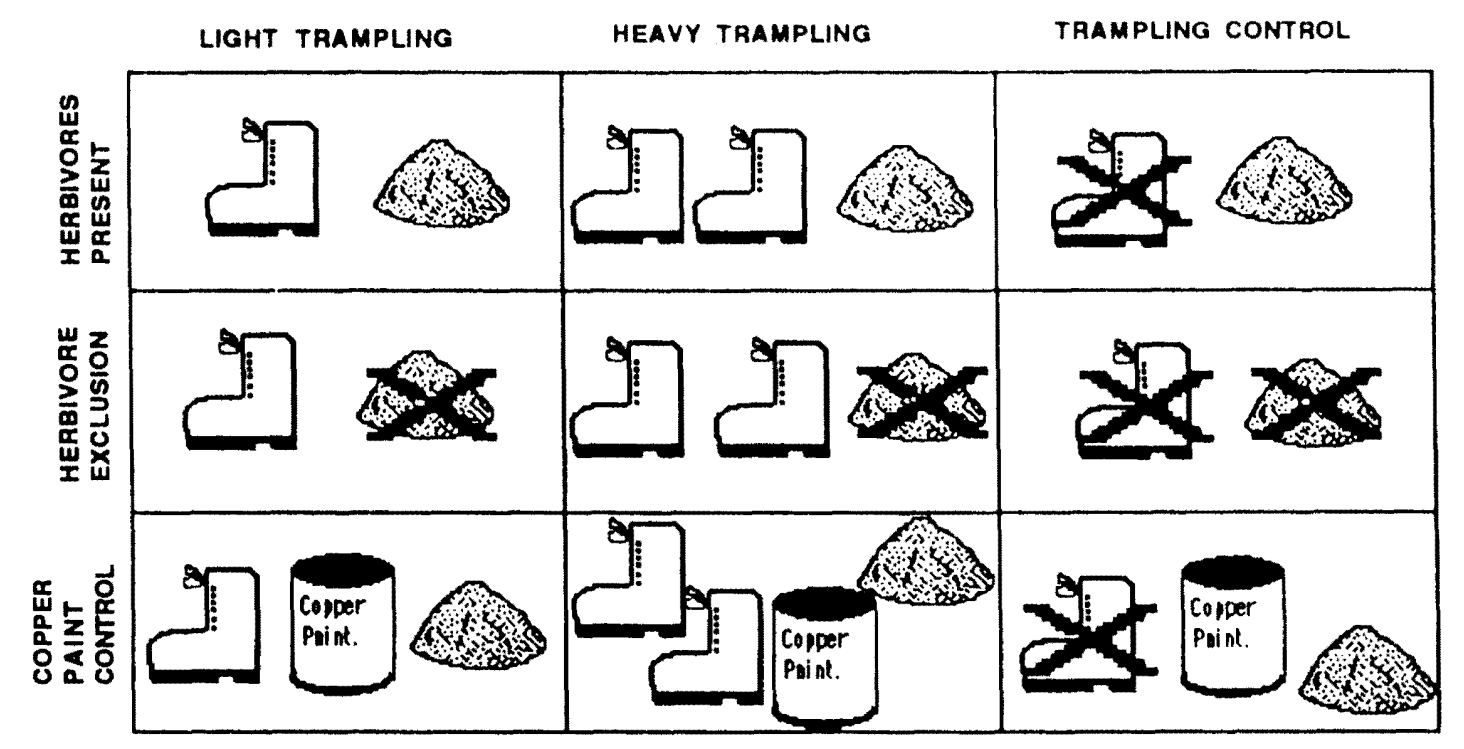


1992 to July 1993 . Light trampling consisted of 150 single footsteps per plot per month. Heavy trampling consisted of 300 single footsteps per plot per month. These intensities were based on previous studies at frequently visited sites on the Oregon coast. Brosnan and Crumrine (1992a) found that species on frequently used sites are trampled up to 228 times per hour. During the recovery phase the monthly application of trampling was stopped for 15 months, from August 1993 and October 1994.

Herbivores were excluded from herbivore exclusion treatments by painting a barrier of copper-based antifouling paint around the experimental plots (Cubit 1984). The paint was applied in a $5 \mathrm{~cm}$ wide band around the plots. Herbivore paint controls were used to test for any effects of copperpaint. Paint was applied in two $10 \mathrm{~cm}$ wide bands at opposite sides of the plots. This allowed herbivores access only through the two paint-free sides. Herbivores were removed from the herbivore-exclusion treatments by hand. Herbivore treatments were maintained through both the trampling and recovery phases. On each sampling date, herbivore-exclusion plots were searched for grazers and any present were removed. As paint barriers deteriorated they were repainted.

The trampling phase extended from November 1992 to July 1993. During this period nine monthly observations were made. The recovery 
phase extended from August 1993 and October 1994. During this period thirteen monthly observations were made, with no observations taken on two months (November 1993 and May 1994) due to adverse conditions. Data were collected during both phases on percent cover and identity of species occupying primary space and secondary (canopy) space. For algae and barnacles, primary percent cover is defined as direct attachment to the substrate. For algae, canopy cover is the percent of the rock surface that a species covers, although it may not be attached at that particular point. Percent cover was determined by using a transparent vinyl sheet $(10 \mathrm{~cm}$ by $10 \mathrm{~cm}$ ) marked with 100 randomly spaced dots. The sheet was laid directly over the plots, and any species under a dot was recorded.

\section{Data Analysis}

Data from the trampling and recovery phases was analyzed separately. Raw data were tested for homogeneity of variance using Hartley's test $(p<0.05)$ (Sokal and Rohlf 1981). Variances were not homoscedastic, and data were arcsine transformed to give homogeneity (Hartley's test $p<0.05$ ). Transformed data were then analyzed using a repeated measures analysis of variance (RMANOVA) on the program Systat (Systat Inc. 1990). RMANOVA were carried out on each species to test for significant changes in mean cover over time in the treatment combinations. 
Special attention was given to trampling, herbivore and trampling herbivore effects. Also noted were block and site differences. As sites were so different in species composition, blocks were nested within sites during the RMANOVA. The Post Hoc test, Student-Newman-Keuls (SNK) was carried out on any treatments that showed significant results. The results of the RMANOVA are summarized in the results section. 


\section{RESULTS}

\section{TRAMPLING PHASE:}

\section{Barnacles}

Balanus glandula (Table 3, Figs. 4 and 5)

Balanus glandula density and distribution were patchily distributed between sites and between blocks and plots within each site throughout the

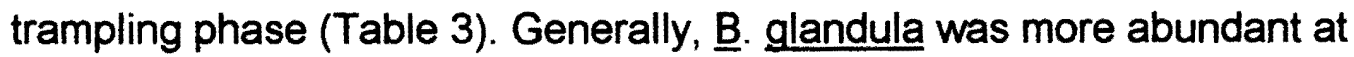
Yaquina Head with distribution between blocks heterogenic. Balanus glandula was less abundant at Fogarty Creek but more homogenously distributed among blocks.

Trampling significantly reduced barnacle abundance at Fogarty Creek and Yaquina Head (Table 3; Figs 4 and 5 ). This effect occurred within one month of the first trampling (Figs 4 and 5). At Fogarty Creek, where B. glandula was less abundant, mean cover in trampled plots declined from $37.6 \%$ in November to $9.2 \%$ in December 1992 (Fig 4), Balanus glandula mean cover in control plots during the same period declined from $46.7 \%$ to

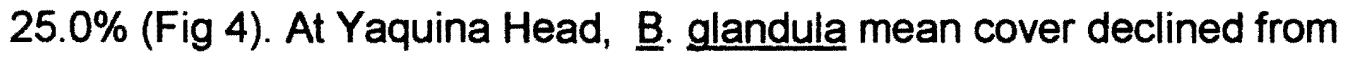
$66 \%$ to $7.8 \%$ in trampled plots between November and December 1992 (Fig 5). At the same time, B. glandula mean cover in control plots declined from $67.3 \%$ in November to $58.6 \%$ in December 1992 (Fig 5). 
Trampling continued to reduce $\underline{B}$. glandula mean cover throughout the experiment. Mean cover in trampled plots remained lower than the mean cover in control plots in all cases except March 1993 at Fogarty Creek (Fig 4). There were no significant differences in mean cover between light trampling and heavy trampling on any date at either site (Table 3). Light trampling removed almost all $\underline{B}$. glandula individuals, and additional trampling had no further effect.

Balanus glandula recruited in March 1993, as shown by an increase in mean cover, in all plots at both sites (Figs 4 and 5). At Yaquina Head, the level of recruitment did not compensate for the effects of trampling and mean cover in trampled plots remained significantly lower than mean cover in control plots (Fig 5). In contrast, at Fogarty Creek (where barnacle abundance is lower) recruitment into trampled plots was sufficient to compensate for trampling effects (Fig 4). However, subsequent trampling

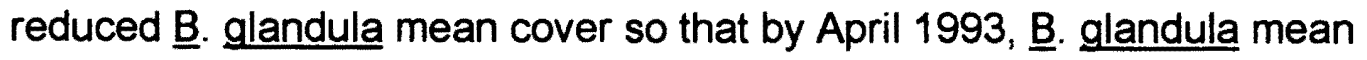
cover was again significantly lower in trampled plots. However, $\underline{B}$ glandula mean cover did not decline to pre-recruitment mean cover at either site (Figs 4 and 5). There were no further recruitment pulses during the trampling phase. 
Figure 4. Effect of trampling on Balanus glandula at Fogarty Creek in the presence and absence of herbivores. Data points represent the mean, and vertical bars are $\pm 1 \mathrm{SE}$.
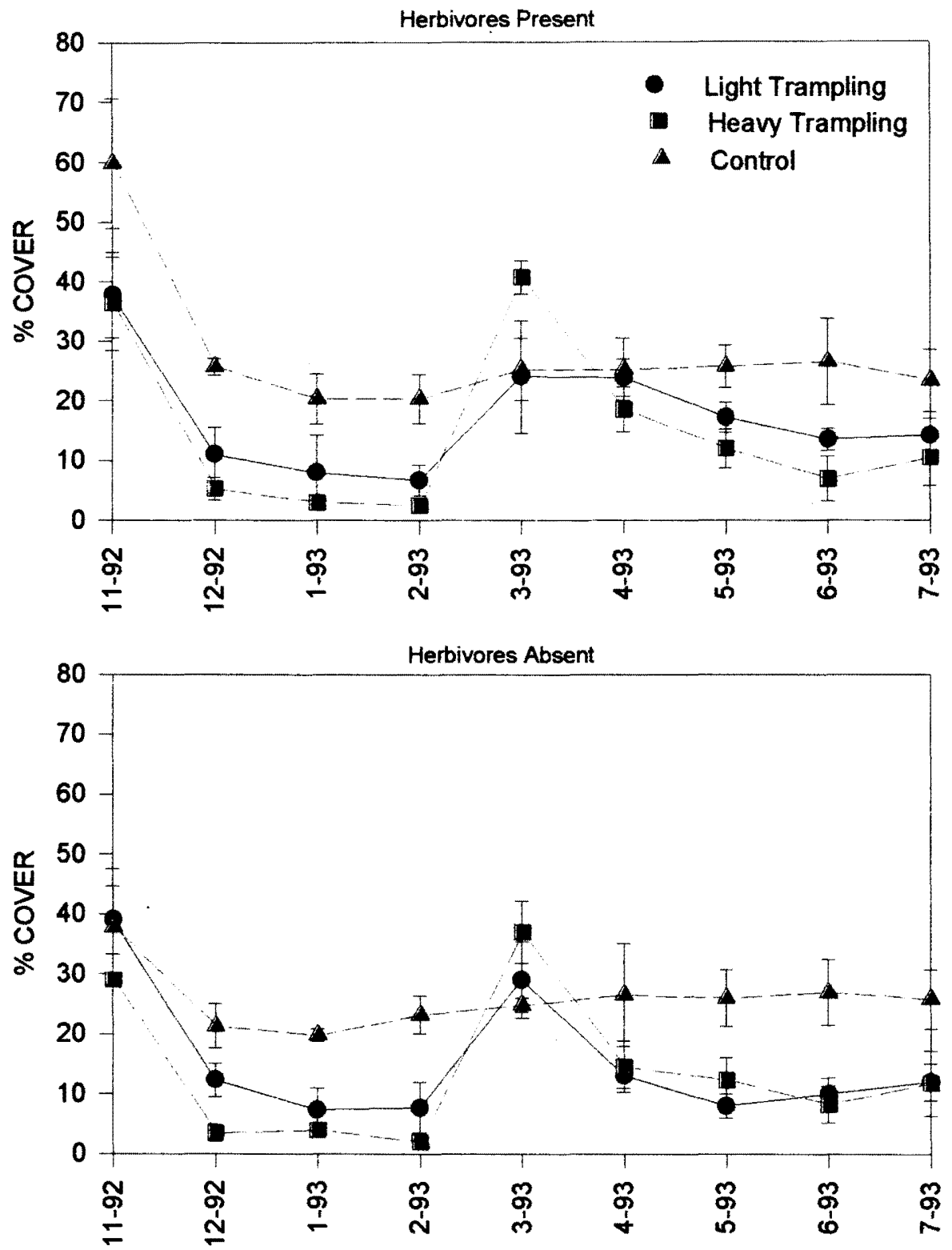
Figure 5. Effect of trampling on Balanus glandula at Yaquina Head in the presence and absence of herbivores. Data points represent the mean, and vertical bars are $\pm 1 \mathrm{SE}$.
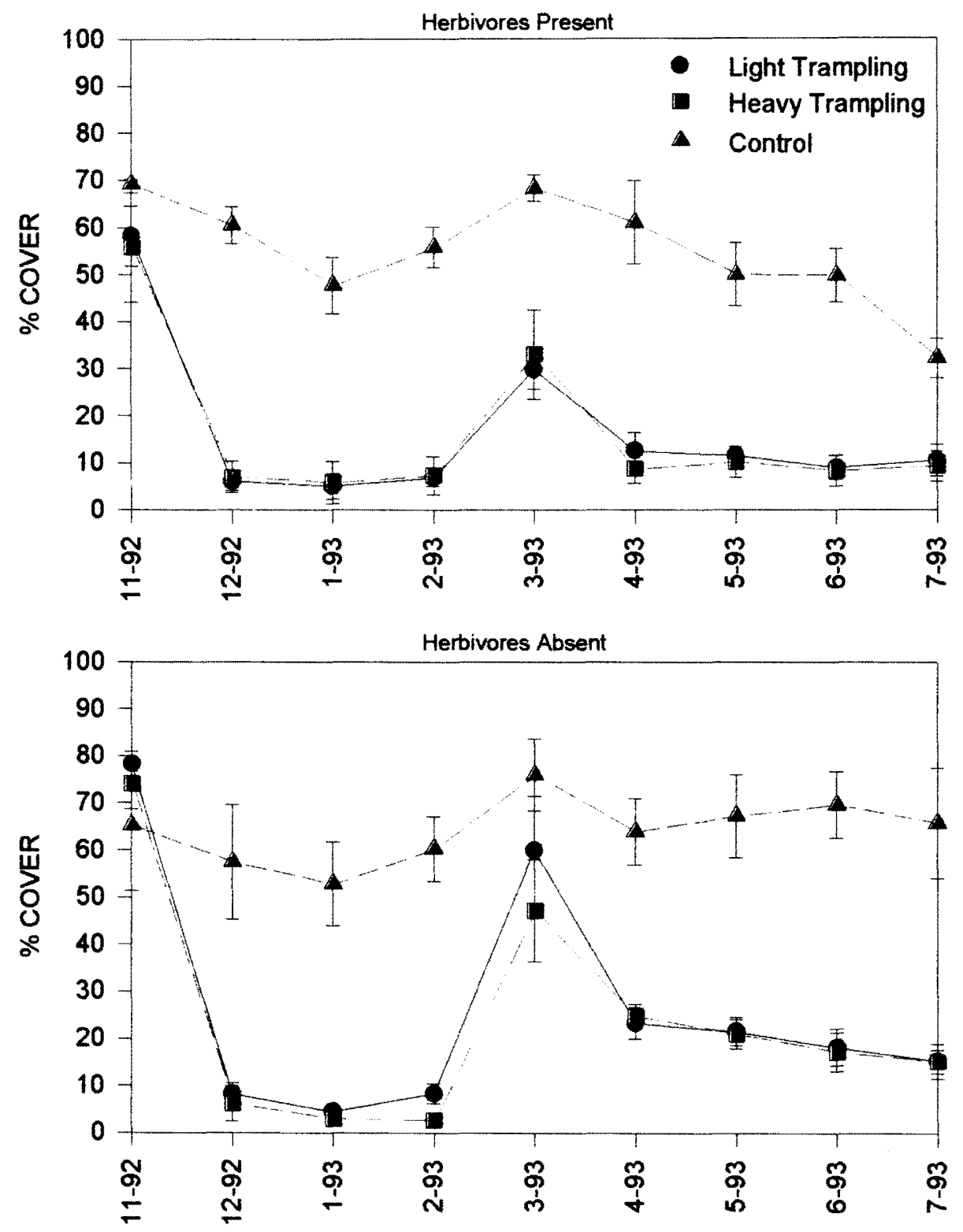
Table 3. Summary of RMANOVA on abundance of barnacles (Balanus glandula) in the trampling phase. Data were arcsine -transformed prior to analysis.

\begin{tabular}{lcccl}
\hline SOURCE & DF & MS & F & P \\
\hline Between treatments & & & & \\
Site & 1 & 3.605 & 64.331 & $\mathrm{P}<0.05$ \\
Block\{Site\} & 6 & 0.140 & 2.496 & $\mathrm{P}<0.05$ \\
Trampling\{Site\} & 4 & 4.466 & 79.702 & $\mathrm{P}<0.05$ \\
Herbivore\{Site\} & 4 & 0.207 & 3.692 & $\mathrm{P}<0.05$ \\
Trampling*Herbivore & 4 & 0.006 & 0.115 & 0.976 \\
Error & 52 & 0.056 & &
\end{tabular}

\section{Within treatments}

\begin{tabular}{lcccl}
\hline Date & 8 & 1.816 & 142.473 & $\mathrm{P}<0.05$ \\
Date*Site & 8 & 0.058 & 4.568 & $\mathrm{P}<0.05$ \\
Date*Block\{Site\} & 48 & 0.027 & 2.096 & $\mathrm{P}<0.05$ \\
Date*Trampling\{Site\} & 32 & 0.106 & 8.291 & $\mathrm{P}<0.05$ \\
Date*Herbivore\{Site\} & 32 & 0.016 & 1.245 & 0.173 \\
Date*Trampling*Herbivore & 32 & 0.019 & 1.458 & 0.054 \\
Error & 416 & 0.013 & &
\end{tabular}

Greenhouse-Geisser Epsilon: 0.6158: Huyn-Feldt Episilon: 0.9366

Herbivores had no effect on $\underline{B}$. glandula cover at Fogarty Creek (Table 3). However, at Yaquina Head herbivores had a significant effect on barnacle abundance, beginning when $\underline{B}$. glandula recruited in March 1993. The rate of barnacle loss from trampled plots with herbivores present was higher than from trampled plots without herbivores. For instance, in April 1993 , one month after recruitment, in trampled plots, mean cover was $14 \%$ 
in herbivore inclusion plots and $27 \%$ in herbivore exclusion treatments (Fig.

$5)$.

Herbivores continued to have a negative effect on $\underline{B}$. glandula throughout the experimental period. Limpets as well as trampling reduced barnacle cover. Consequently, B. glandula cover was significantly lower in trampled plots with herbivores than in trampled plots without herbivores (Fig. 5). 
Chthamalus dalli (Table 4, Figs 6 and 7)

Chthamalus dalli abundance was low prior to trampling at both sites, $1.3 \%$ at Fogarty Creek, and $0.03 \%$ at Yaquina Head (Figs 6 and 7 ). The distribution of $\underline{C}$. dalli was also spatially heterogenic within each site (Table 4). For example, at Yaquina Head, $\underline{\underline{C}}$. dalli mean cover was higher in herbivore inclusion plots than in herbivore exclusion plots (Fig. 7 ).

Trampling had no negative effects on $\underline{\mathrm{C}}$. dalli abundance at either site. Instead, there were indirect positive effects with mean cover of $\underline{\underline{C}}$. dalli increasing as a result of the reduction $\underline{B}$. glandula (Table 4). At Yaquina Head, $\underline{C}$. dalli mean cover increased gradually in all plots. However, $\underline{C}$. dalli was never abundant, and maximum mean cover was less than $15 \%$ (Fig. 7). At Fogarty Creek, $\underline{\mathrm{C}}$. dalli mean cover gradually increased and became more abundant than at Yaquina Head (Fig 6). At Fogarty Creek, $\underline{\mathrm{C}}$ dalli mean cover reached $35 \%$ in some trampled plots (Fig. 6). There were two discernable recruitment pulses in February 1993, and a larger settlement pulse in July 1993 (Figs 6 and 7).

Chthamalus dalli mean cover in control plots increased slightly through the trampling phase. However, mean cover remained low (Figs 6 and 7). There were no herbivore effects at either site (Table 4). There was also no significant difference between light and heavy trampling. 
Figure 6. Effect of trampling on Chthamalus dalli at Fogarty Creek in the presence and absence of herbivores. Data points represent the mean, and vertical bars are $\pm 1 \mathrm{SE}$.
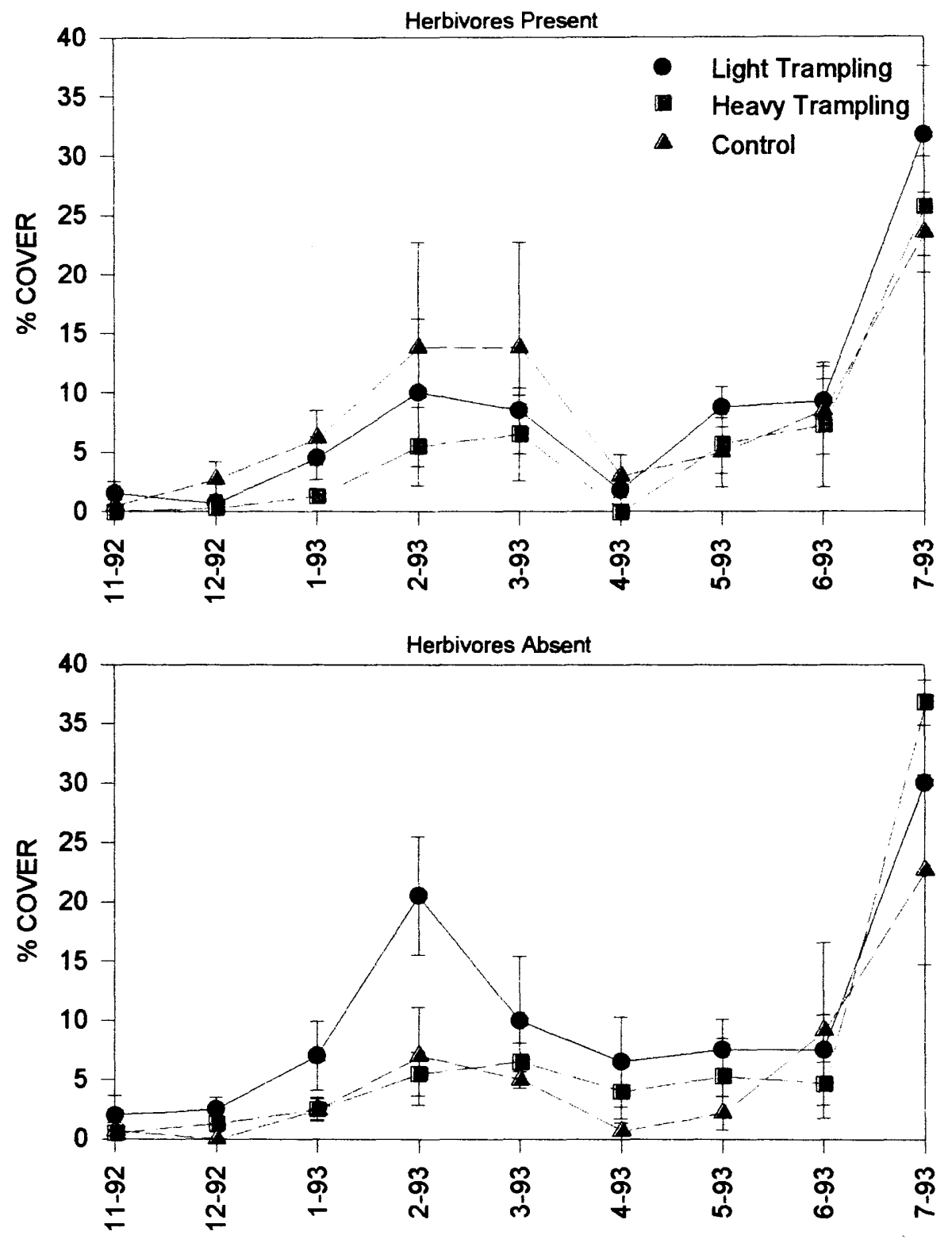
Figure 7. Effect of trampling on Chthamalus dalli at Yaquina Head in the presence and absence of herbivores. Data points represent the mean, and vertical bars are $\pm 1 \mathrm{SE}$.
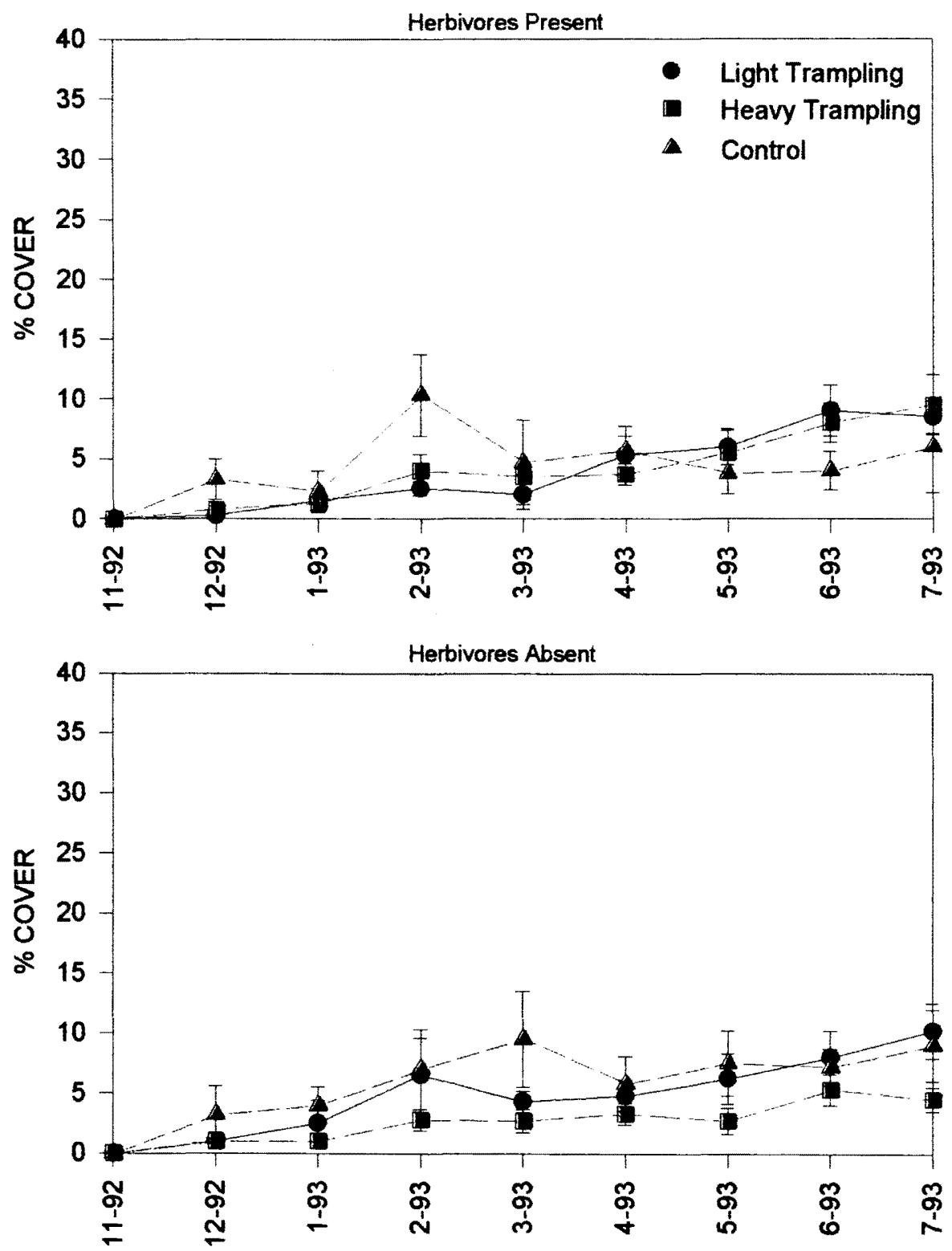
Table 4. Summary of RMANOVA on abundance of barnacles (Chthamalus dalli) in the trampling phase. Data were arcsine -transformed prior to analysis.

\begin{tabular}{lllll}
\hline SOURCE & DF & MS & F & P \\
\hline
\end{tabular}

\section{Between treatments}

Site

Block\{site\}

Trampling\{site\}

Herbivore\{site\}

Trampling*Herbivore

Error

$\begin{array}{cccl}1 & 0.515 & 14.132 & P<0.05 \\ 6 & 0.144 & 3.951 & P<0.05 \\ 4 & 0.044 & 1.196 & 0.324 \\ 4 & 0.027 & 0.742 & 0.568 \\ 4 & 0.021 & 0.584 & 0.676 \\ 52 & 0.036 & & \end{array}$

\section{Within treatments}

\begin{tabular}{lcccl}
\hline Date & 8 & 0.936 & 117.415 & $\mathrm{P}<0.05$ \\
Date*Site & 8 & 0.185 & 23.247 & $\mathrm{P}<0.05$ \\
Date*Block\{site\} & 48 & 0.024 & 3.057 & $\mathrm{P}<0.05$ \\
Date*Trampling\{site\} & 32 & 0.013 & 1.659 & $\mathrm{P}<0.05$ \\
Date*Herbivore\{site\} & 32 & 0.010 & 1.312 & 0.123 \\
Date*Trampling*Herbivore & 32 & 0.009 & 1.131 & 0.289 \\
Error & 416 & 0.008 & &
\end{tabular}

Greenhouse-Geisser Epsilon: 0.6909: Huyn-Feldt Episilon: 1.0000 


\section{Fucoid algae}

Density and distribution of fucoid Algae were spatially heterogous between sites and between blocks and plots within each site throughout the trampling phase (Tables 5 and 6 ). Generally, fucoid algae were more abundant at Fogarty Creek compared to Yaquina Head. At Fogarty Creek, fucoid density and distribution were more spatially homogenic, while at Yaquina Head fucoid density and distribution were heterogenic to the extreme where blocks lacked fucoids. Fucoids are very susceptible to trampling. Results for canopy and primary cover are presented separately.

\section{Canopy Cover (Table 5; Figs 8 and 9)}

At Fogarty Creek in December 1992 (after one application of trampling), mean cover had declined from an average of $11.0 \%$ in November 1992 to $0.9 \%$ in December 1992 in herbivore inclusion treatments, and from $12.8 \%$ in November 1992 to $0.7 \%$ in December 1992 in herbivore exclusion treatments (Fig 8). There was no difference in canopy loss between light and heavy trampling (Table 5). Trampling and the lack of facilitative species prevented foliose algae from significant recovery.

At Fogarty Creek, canopy cover in control plots remained relatively high and showed seasonal fluctuations. Canopy mean cover ranged from 
$5.5 \%$ in November 1992 to $27 \%$ in March 1993 in herbivore inclusion plots (Fig 8). Canopy cover in control plots fluctuated more than canopy cover in trampled plots, which remained at $<15 \%$ cover throughout the experimental period (Fig 8). At Fogarty Creek, canopy cover declined in herbivore inclusion plots between May and July 1993. These declines were the result of harbor seals, Phoca vitulina, using blocks 2 and 3 as haul-out areas. Herbivores did not significantly affect mean canopy cover of fucoids. In addition, there were no herbivore-trampling interactions: Trampling was the only significant factor (Table 5). This implies that trampling swamps any potential herbivore effects on recruitment or colonization of algae.

At Yaquina Head, canopy mean cover was low, $8.5 \%$ in November 1992 (Fig 9). Canopy cover in trampled plots declined to zero within two months of trampling. Canopy cover did not recover in herbivore inclusion plots during the trampling phase. Canopy cover in herbivore exclusion plots ranged from 0\% to 3\% (Fig 9). Canopy cover in the control plots increased throughout the spring, and declined in summer (Fig 9).

Canopy cover was most abundant in herbivore inclusion plots due to the heterogenic distribution of fucoids (Table 5; Fig. 9). Initial cover ranged from $14 \%$ to $40 \%$ in control, herbivore-exclusion plots. By chance, experimental plots that were randomly assigned as herbivore inclusion 
Figure 8. Effect of trampling on Fucoid Algae (Canopy) at Fogarty Creek in the presence and absence of herbivores. Data points represent the mean, and vertical bars are $\pm 1 \mathrm{SE}$.
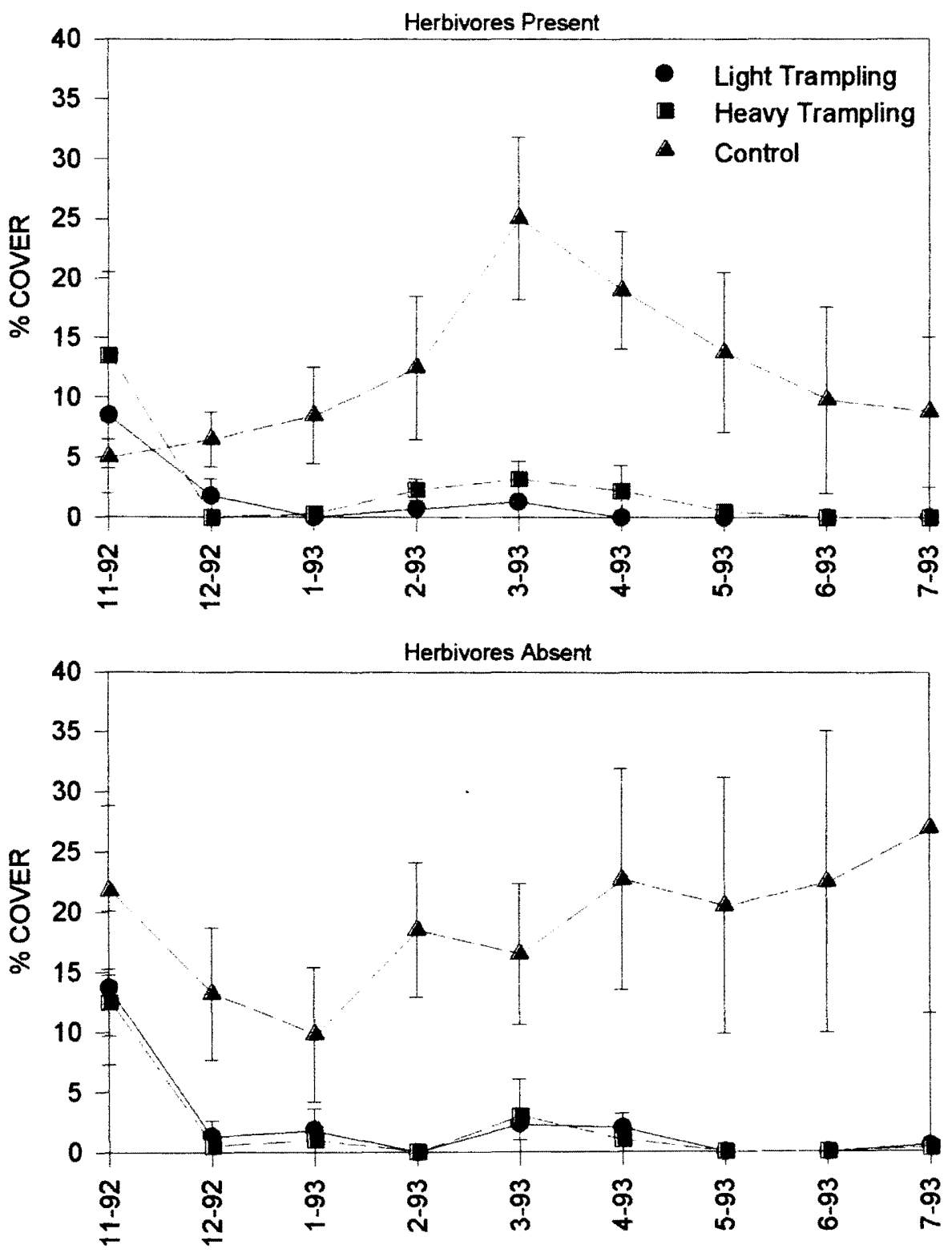
Figure 9. Effect of trampling on Fucoid Algae (Canopy) at Yaquina Head in the presence and absence of herbivores. Data points represent the mean, and vertical bars are $\pm 1 \mathrm{SE}$.
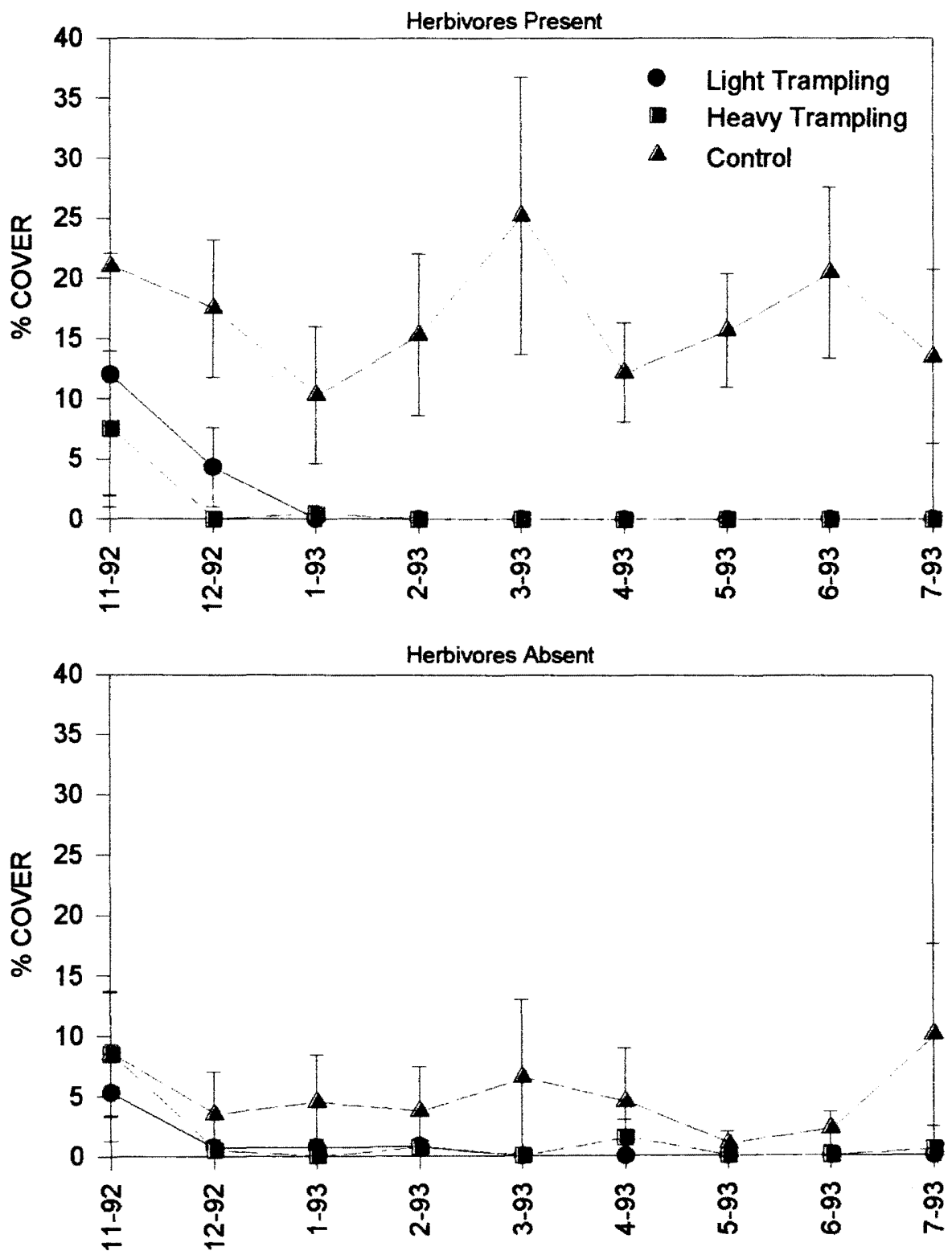
Table 5. Summary of RMANOVA on abundance of Fucoid Algae (canopy) in the trampling phase. Data were arcsine -transformed prior to analysis.

\begin{tabular}{lclll}
\hline SOURCE & DF & MS & F & P \\
\hline Between treatments & & & & \\
Site & 1 & 0.137 & 24.820 & $\mathrm{P}<0.05$ \\
Block\{Site\} & 6 & 0.013 & 2.282 & $\mathrm{P}<0.05$ \\
Trampling\{Site\} & 4 & 0.195 & 35.305 & $\mathrm{P}<0.05$ \\
Herbivore\{Site\} & 4 & 0.003 & 0.559 & 0.693 \\
Trampling*Herbivore & 4 & 0.004 & 0.659 & 0.623 \\
Error & 52 & 0.006 & &
\end{tabular}

Within treatments

\begin{tabular}{lcccl}
\hline Date & 8 & 0.004 & 1.631 & 0.114 \\
Date*Site & 8 & 0.012 & 5.259 & $\mathrm{P}<0.05$ \\
Date*Block\{Site\} & 48 & 0.006 & 2.489 & $\mathrm{P}<0.05$ \\
Date*Trampling\{Site\} & 32 & 0.005 & 1.989 & $\mathrm{P}<0.05$ \\
Date*Herbivore\{Site\} & 32 & 0.004 & 1.789 & $\mathrm{P}<0.05$ \\
Date*Trampling*Herbivore & 32 & 0.003 & 1.233 & 0.183 \\
Error & 416 & 0.002 & &
\end{tabular}

Greenhouse-Geisser Epsilon: 0.6254: Huyn-Feldt Episilon: 0.9529

treatments had a greater cover of fucoids. By contrast, in herbivore exclusion plots and paint control plots, initial fucoid mean cover was less than $10 \%$.

There was no difference between control plots in herbivore exclusion plots and paint control (herbivore inclusion) plots during the experiment. This effect was carried through the trampling phase. So the significance of herbivores (Table 5) is actually not due to herbivore effects. 
Primary cover (Table 6; Figs 10 and 11)

Two months after trampling was begun primary cover of fucoids declined significantly (Table 6; Figs 10 and 11). At Fogarty, Creek primary cover in trampled plots remained below $5 \%$ for the remainder of the trampling phase (Fig 10). By contrast, primary cover in control plots gradually increased during spring. At Fogarty Creek, there was no difference between the effects of light and heavy trampling. Both reduced fucoid primary cover to the same level. At the beginning of the experiment (prior to any trampling), algal cover was higher in the herbivore exclusion treatments (Fig 10). This was not due to any trampling effect. However, after trampling started, herbivores had no effect on trampled plots: Cover in herbivore inclusion and exclusion plots in trampled treatments was the same, and cover in herbivore inclusion and exclusion plots in control treatments was also the same (Table 6; Fig 10 ).

Primary cover of fucoid algae at Yaquina Head was low. Trampling reduced mean cover to $0 \%$ within two months of trampling (Fig 11). There was some recruitment in April in herbivore inclusion plots but these plants disappeared a month later (Fig 11). In control plots, fucoid primary cover increased and was most abundant in the herbivore inclusion plots (for reasons explained above). 
Figure 10. Effect of trampling on Fucoid Algae (Primary) at Fogarty Creek in the presence and absence of herbivores. Data points represent the mean, and vertical bars are $\pm 1 \mathrm{SE}$.
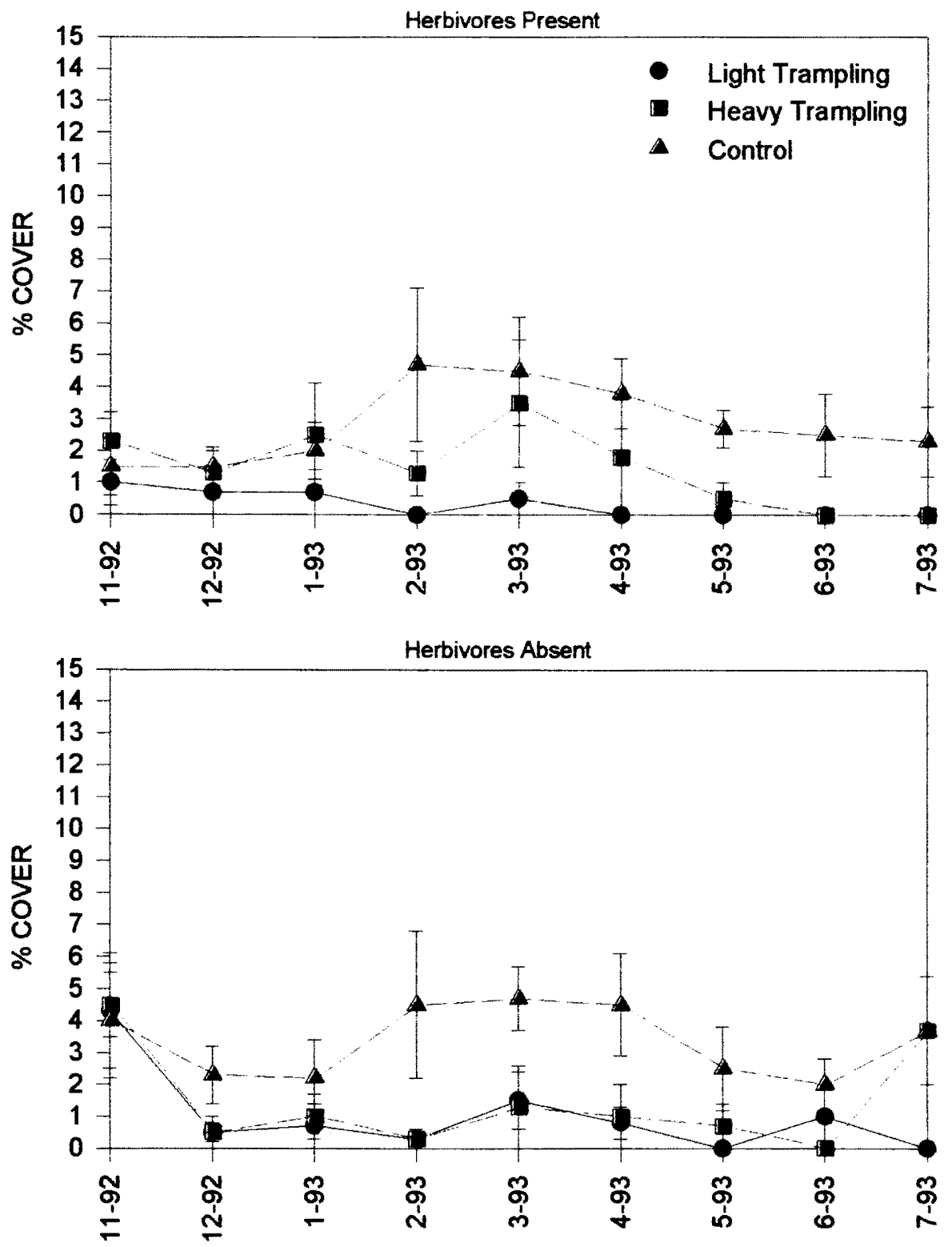
Figure 11. Effect of trampling on Fucoid Algae (Primary) at Yaquina Head in the presence and absence of herbivores. Vertical bars are $\pm 1 \mathrm{SE}$.
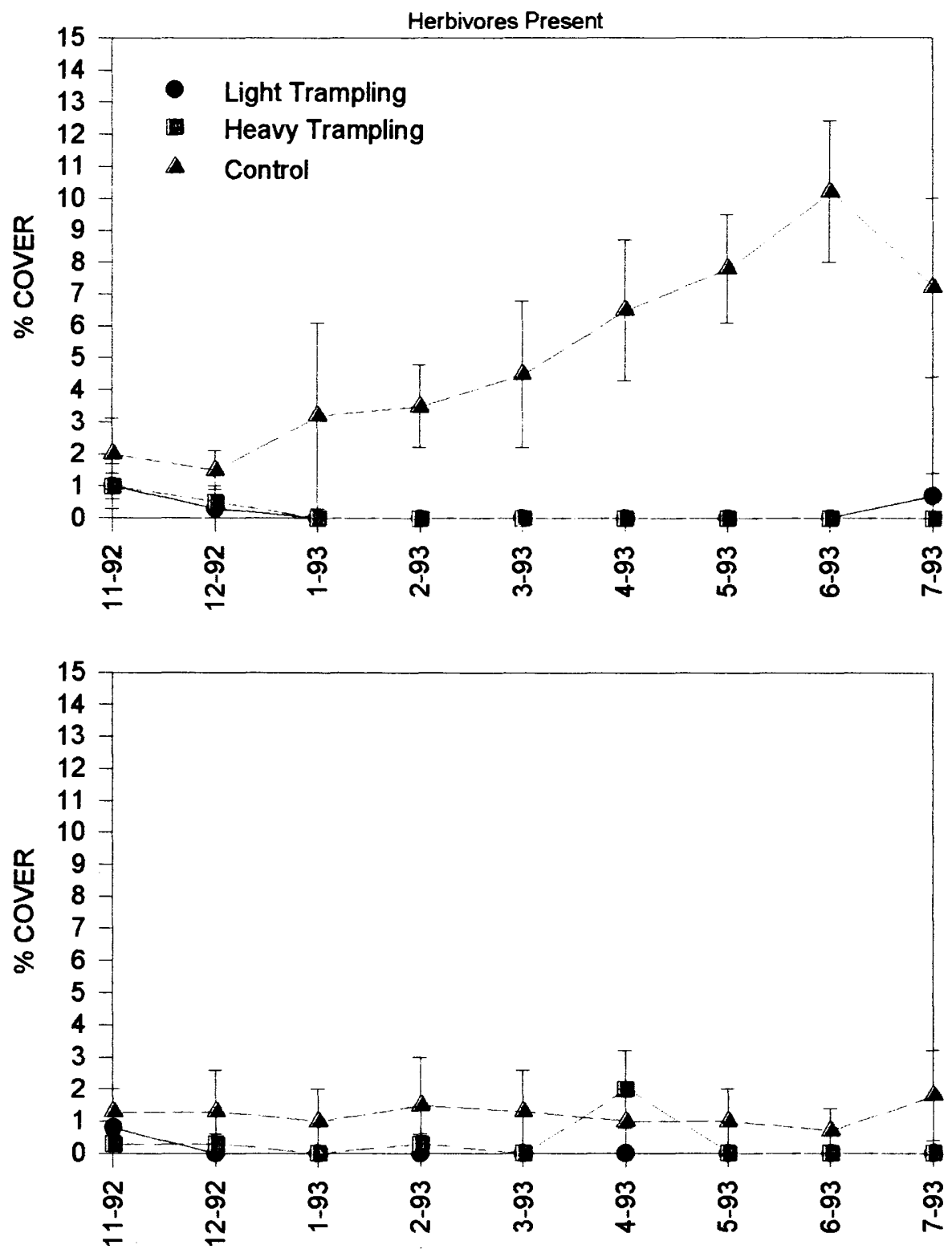
Table 6. Summary of RMANOVA on abundance of Fucoid Algae (primary) in the trampling phase. Data were arcsine -transformed prior to analysis.

\begin{tabular}{lclll}
\hline SOURCE & DF & MS & F & P \\
\hline Between treatments & & & & \\
Site & 1 & 0.151 & 24.861 & $\mathrm{P}<0.05$ \\
Block\{Site\} & 6 & 0.011 & 1.753 & 0.127 \\
Trampling\{Site\} & 4 & 0.118 & 19.442 & $\mathrm{P}<0.05$ \\
Herbivore\{Site\} & 4 & 0.001 & 0.207 & 0.934 \\
Trampling*Herbivore & 4 & 0.004 & 0.600 & 0.665 \\
Error & 52 & 0.006 & &
\end{tabular}

\section{Within treatments}

\begin{tabular}{|c|c|c|c|c|}
\hline Date & 8 & 0.003 & 2.250 & $P<0.05$ \\
\hline Date ${ }^{\star}$ Site & 8 & 0.005 & 4.140 & $P<0.05$ \\
\hline Date*Block $\{$ Site $\}$ & 48 & 0.003 & 2.540 & $P<0.05$ \\
\hline Date*Trampling $\{$ Site $\}$ & 32 & 0.003 & 2.102 & $P<0.05$ \\
\hline Date*Herbivore $\{$ Site $\}$ & 32 & 0.002 & 1.447 & 0.058 \\
\hline Date ${ }^{\star}$ Trampling*Herbivore & 32 & 0.001 & 0.546 & 0.980 \\
\hline Error & 416 & 0.001 & & \\
\hline
\end{tabular}

Greenhouse-Geisser Epsilon: 0.6254: Huyn-Feldt Episilon: 0.9529 
Endocladia muricata (Table 7, Figure 12)

Endocladia muricata abundance at Yaquina Head was very low and patchily distributed. For these reasons, data on this species at the Yaquina Head site are not included as they could not be analyzed or graphed. At Fogarty Creek, E. muricata was rarely attached directly to primary substrate. The majority of $\underline{E}$. muricata individuals grew as epibionts on barnacles (predominantly $\underline{\text { B. glandula). Trampling significantly reduced E. muricata }}$ cover beginning in January 1993 (Table 7; Fig. 12). Canopy cover increased in control plots (up to $25 \%$ cover in herbivore inclusion plots), while cover in trampled plots remained low, $>5 \%$ (Fig 12). The effect of trampling intensity on E. muricata was not significant. There were no herbivore effects (Table 7). Endocladia muricata was present only in trace amounts in plots at Yaquina Head, and cover was too low for analysis. 
Figure 12. Effect of trampling on Endocladia muricata at Fogarty Creek in the presence and absence of herbivores. Data points represent the mean, and vertical bars are $\pm 1 \mathrm{SE}$.
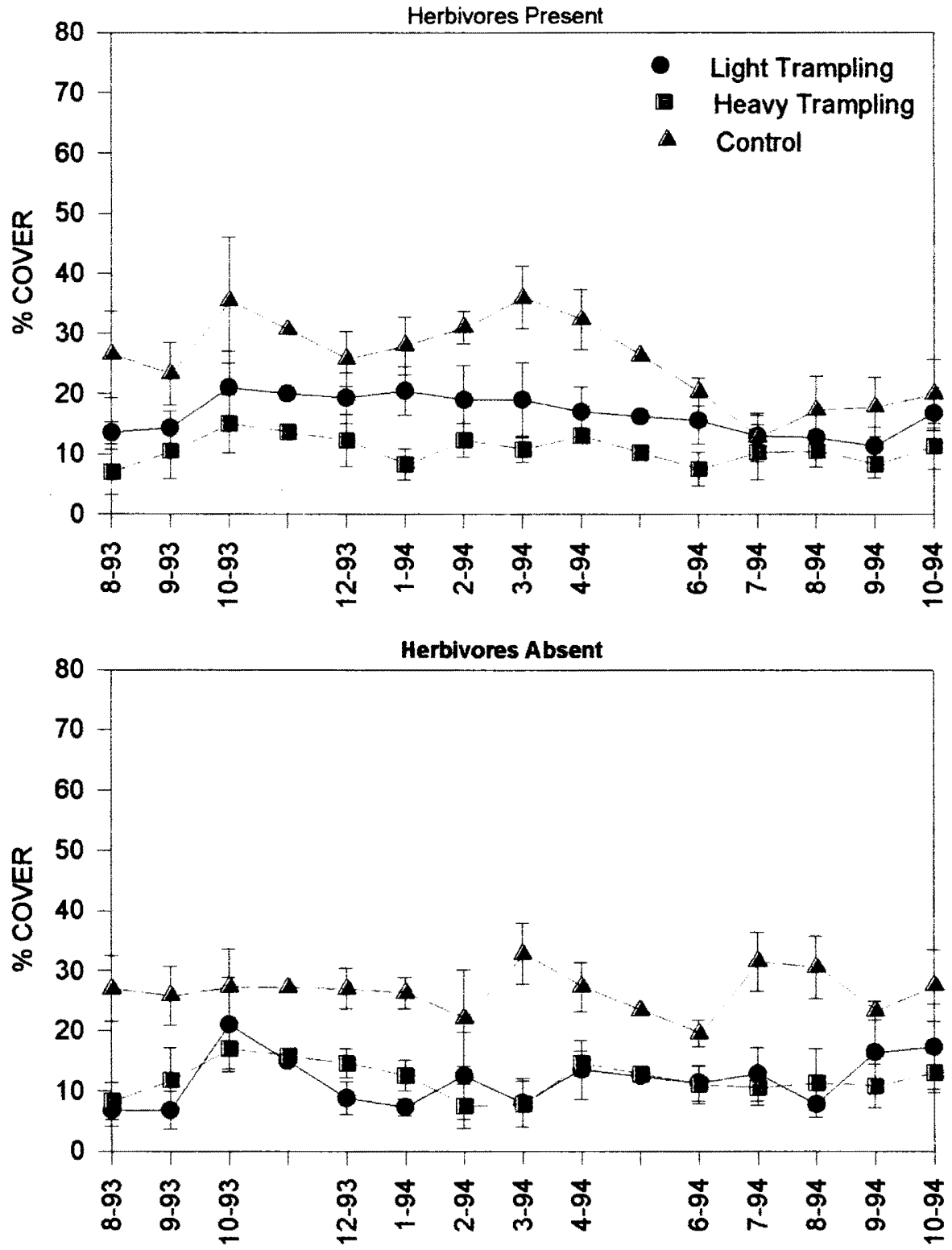
Table 7. Summary of RMANOVA on abundance of (Endocladia muricata) in the trampling phase. Data were arcsine -transformed prior to analysis.

\begin{tabular}{lcccl}
\hline SOURCE & DF & MS & F & P \\
\hline Between treatments & & & & \\
Block & 3 & 0.079 & 2.025 & 0.137 \\
Trampling & 2 & 1.361 & 34.764 & $\mathrm{P}<0.05$ \\
Herbivore & 2 & 0.122 & 3.116 & 0.063 \\
Trampling Herbivore & 4 & 0.075 & 1.911 & 0.141 \\
Error & 24 & 0.039 & &
\end{tabular}

\section{Within treatments}

\begin{tabular}{lcccl}
\hline Date & 8 & 0.062 & 6.782 & $\mathrm{P}<0.05$ \\
Date*Block & 24 & 0.017 & 1.836 & $\mathrm{P}<0.05$ \\
Date*Trampling & 16 & 0.057 & 6.180 & $\mathrm{P}<0.05$ \\
Date*Herbivore & 16 & 0.009 & 0.986 & 0.474 \\
Date*Trampling*Herbivore & 32 & 0.008 & 0.894 & 0.634 \\
Error & 192 & 0.009 & &
\end{tabular}

Greenhouse-Geisser Epsilon: 0.6211: Huyn-Feldt Episilon: 1.0000 


\section{RECOVERY PHASE}

\section{Barnacles:}

Balanus glandula (Table 8; Figs 13 and 14)

The distribution and abundance of $\underline{B}$. glandula is spatially heterogenic within sites and between sites (Table 8). Balanus glandula mean cover remained higher at Yaquina Head compared to Fogarty Creek. Balanus glandula mean cover varied throughout the recovery phase at both sites (Figs 13 and 14). There were no significant recruitment pulses during the recovery phase, unlike the recruitment pulses observed during the trampling phase. Initially mean cover of $\underline{B}$. glandula in trampled plots during the recovery phase was below $15 \%$ at both sites Fogarty Creek: light trampling $9.9 \%$, heavy trampling 9.7\%; Yaquina Head: light trampling $13.3 \%$, heavy trampling 12.7\% (Figs 13 and 14). At Fogarty Creek, B. glandula mean \% cover remained below $20 \%$ in light trampling treatments and below $16.5 \%$ in heavy trampling treatments (Fig 13). At Yaquina Head, B. glandula mean \% cover remained below $36.9 \%$ in light trampling treatments and below $29.7 \%$ in heavy trampling treatments (Fig 14).

In the control plots (no trampling) B. glandula mean cover varied throughout the recovery phase but on average declined. At Fogarty Creek, the initial mean cover was $27.0 \%$; by the conclusion of observations, mean cover was $21.3 \%$ (Fig 13). At Yaquina Head, the initial mean cover was 
$59.5 \%$; by the conclusion of observations mean cover, was $52.8 \%$ (Fig 14). Generally, mean cover in the controls converged with mean cover in the trampling treatments.

There continued to be no significant differences in mean cover of $\underline{B}$. glandula between light and heavy trampling. There was, however, one case on July 1994 at Yaquina Head where mean cover was greater in light trampling (42.1\%) compared to heavy trampling $(27.0 \%)$. At both Fogarty Creek and Yaquina Head there were significant differences in $\underline{B}$. glandula mean cover between each of the trampling treatments (light and heavy) and the controls (Table 8).

There were no significant differences in mean cover of $\underline{B}$. glandula between herbivores present and herbivore exclusion, and herbivores present/exclusion and paint control at Fogarty Creek and Yaquina Head (Table 8). 
Figure 13. Recovery of Balanus glandula at Fogarty Creek in the presence and absence of herbivores. Data points represent the mean, and vertical bars are $\pm 1 \mathrm{SE}$.
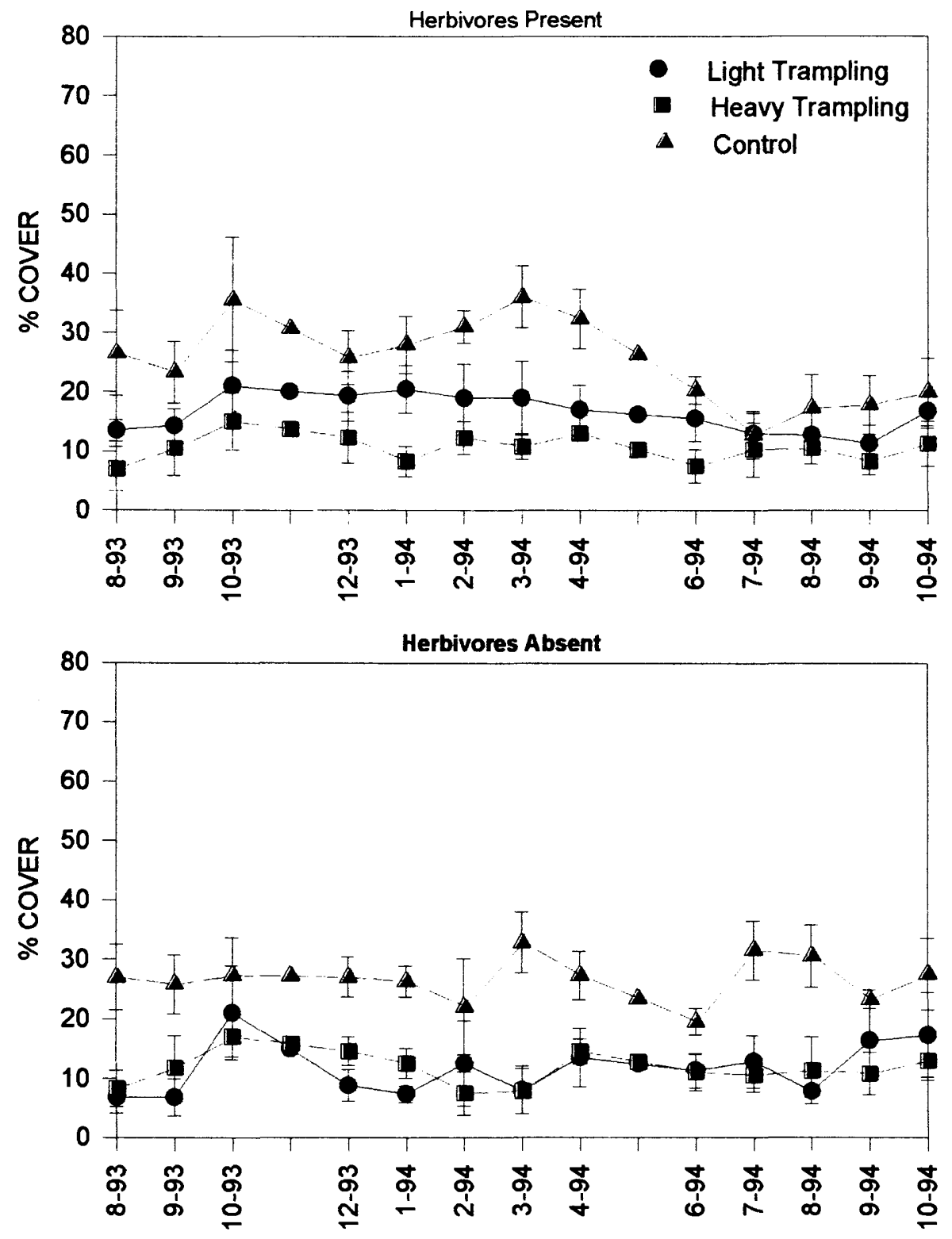
Figure 14. Recovery of Balanus glandula at Yaquina Head in the presence and absence of herbivores. Data points represent the mean, and vertical bars are $\pm 1 \mathrm{SE}$.
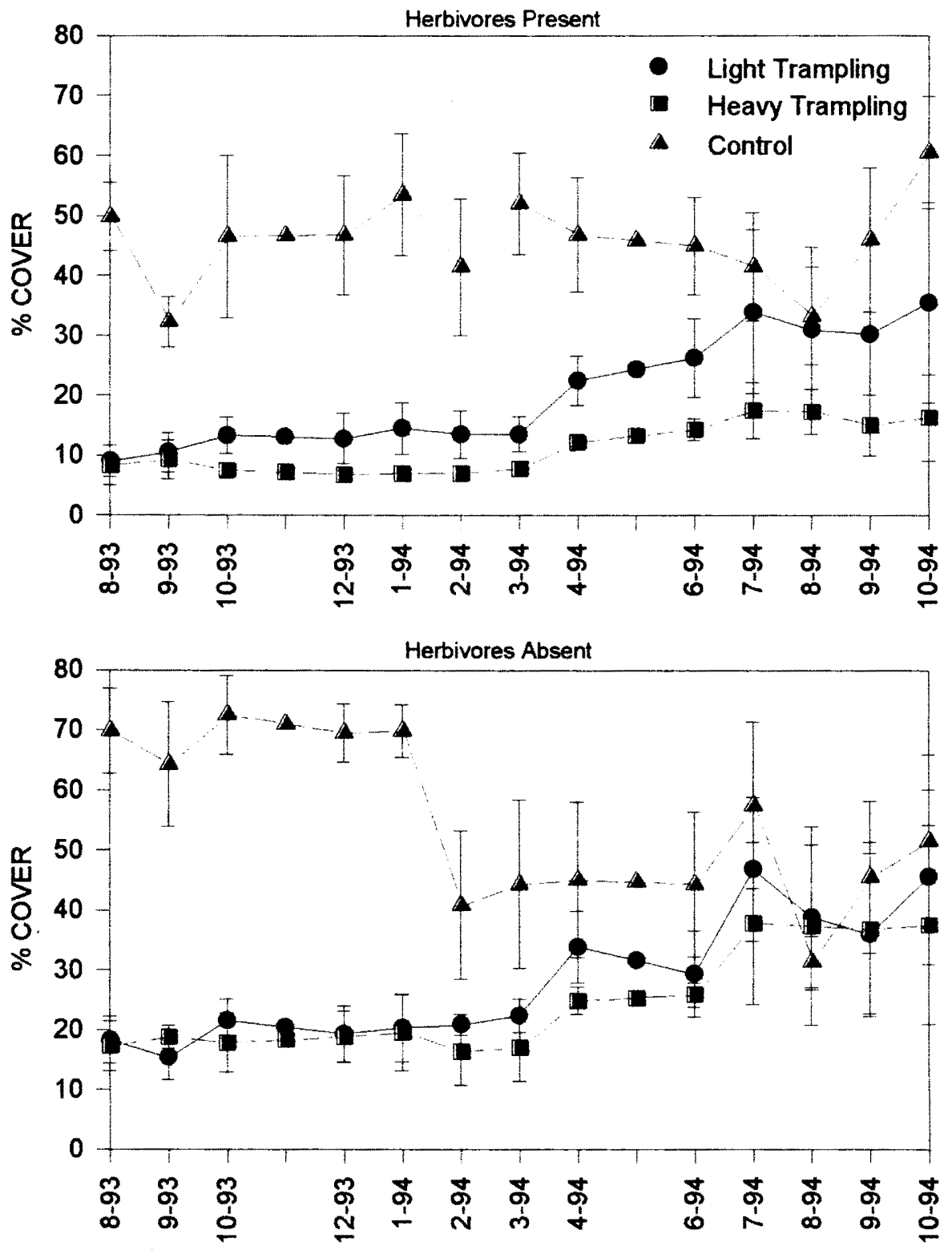
Table 8. Summary of RMANOVA on abundance of barnacles (Balanus glandula) in the recovery phase. Data were arcsine -transformed prior to analysis.

\begin{tabular}{lllll}
\hline SOURCE & DF & MS & F & P \\
\hline Between treatments & & & & \\
Site & 1 & 8.646 & 73.029 & $\mathrm{P}<0.05$ \\
Block\{Site\} & 6 & 0.390 & 3.297 & $\mathrm{P}<0.05$ \\
Trampling\{Site\} & 4 & 4.886 & 41.271 & $\mathrm{P}<0.05$ \\
Herbivore\{Site\} & 4 & 0.447 & 3.772 & $\mathrm{P}<0.05$ \\
Trampling*Herbivore & 4 & 0.188 & 1.587 & 0.192 \\
Error & 52 & 0.118 & &
\end{tabular}

\section{Within treatments}

\begin{tabular}{lllll}
\hline Date & 12 & 0.080 & 5.508 & $\mathrm{P}<0.05$ \\
Date*Site & 12 & 0.123 & 8.469 & $\mathrm{P}<0.05$ \\
Date*Block\{Site\} & 72 & 0.066 & 4.549 & $\mathrm{P}<0.05$ \\
Date*Trampling\{Site\} & 48 & 0.054 & 3.707 & $\mathrm{P}<0.05$ \\
Date*Herbivore\{Site\} & 48 & 0.017 & 1.140 & 0.245 \\
Date*Trampling ${ }^{\star}$ Herbivore & 48 & 0.009 & 0.611 & 0.983 \\
Error & 624 & 0.015 & &
\end{tabular}

Greenhouse-Geisser Epsilon: 0.3342: Huyn-Feldt Episilon: 0.4979 
Chthamalus dalli (Table 9; Figs. 15 and 16)

Chthamalus dalli abundance was low and spatially heterogenic (between sites and within sites) prior to this study (trampling and recovery phase); (Table 9). Chthamalus dalli continued to increase in abundance throughout the recovery phase and remained spatially heterogenic (Table 9). The increase in abundance was due to the near constant recruitment of

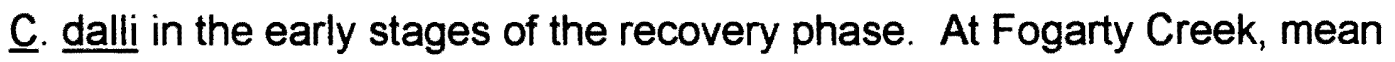
cover was initially $10.0 \%$ in the light trampling treatments and $7.2 \%$ in heavy trampling treatments (Fig 15). There was a large recruitment on September 1993 which peaked by the October 1993 (Fig 15). By the conclusion of the recovery phase mean cover in light trampling was $49.6 \%$ and $42.8 \%$ in heavy trampling (Fig 15). After this point there was a slight decline in $\underline{\mathrm{C}}$. dalli cover. At Yaquina Head mean cover was initially $7.7 \%$ in light trampling treatments and $7.2 \%$ in trampling treatments. Chthamalus dalli recruitment was slow reaching a peak around July 1994 and August 1994 (Fig 16).

In general, mean cover of $\underline{\mathrm{C}}$. dalli in trampling controls was variable at both sites. At Fogarty Creek, $\underline{C}$. dalli mean cover in the trampling treatments exceeded the mean cover in the trampling controls (Fig 15). At Fogarty Creek mean cover in the trampling controls increased from an initial mean cover of $9.3 \%$ to $13.9 \%$ by the end of the recovery phase (Fig 15). At 
Yaquina Head, mean cover in the trampling control decreased from an initial cover of $6.6 \%$ to $1.7 \%$ by the end of the recovery phase (Fig 16 ).

Mean cover of $\underline{\mathrm{C}}$. dalli was significantly higher in light and heavy trampling treatments compared to the controls at all dates except the first date (August 1993) at Fogarty Creek (Table 9). At Yaquina Head, mean cover of $\underline{C}$. dalli was significantly greater in light and heavy trampling treatments compared to the controls at all dates except the first two dates (August 1993 and September 1993). At Fogarty Creek there were no significant differences in C. dalli mean cover between light and heavy trampling at both sites. There were no significant differences in mean cover of $\underline{\mathrm{C}}$. dalli between herbivores present and herbivore exclusion on any dates and at both sites. 
Figure 15. Recovery of Chthamalus dalli at Fogarty Creek in the presence and absence of herbivores. Data points represent the mean, and vertical bars are $\pm 1 \mathrm{SE}$.
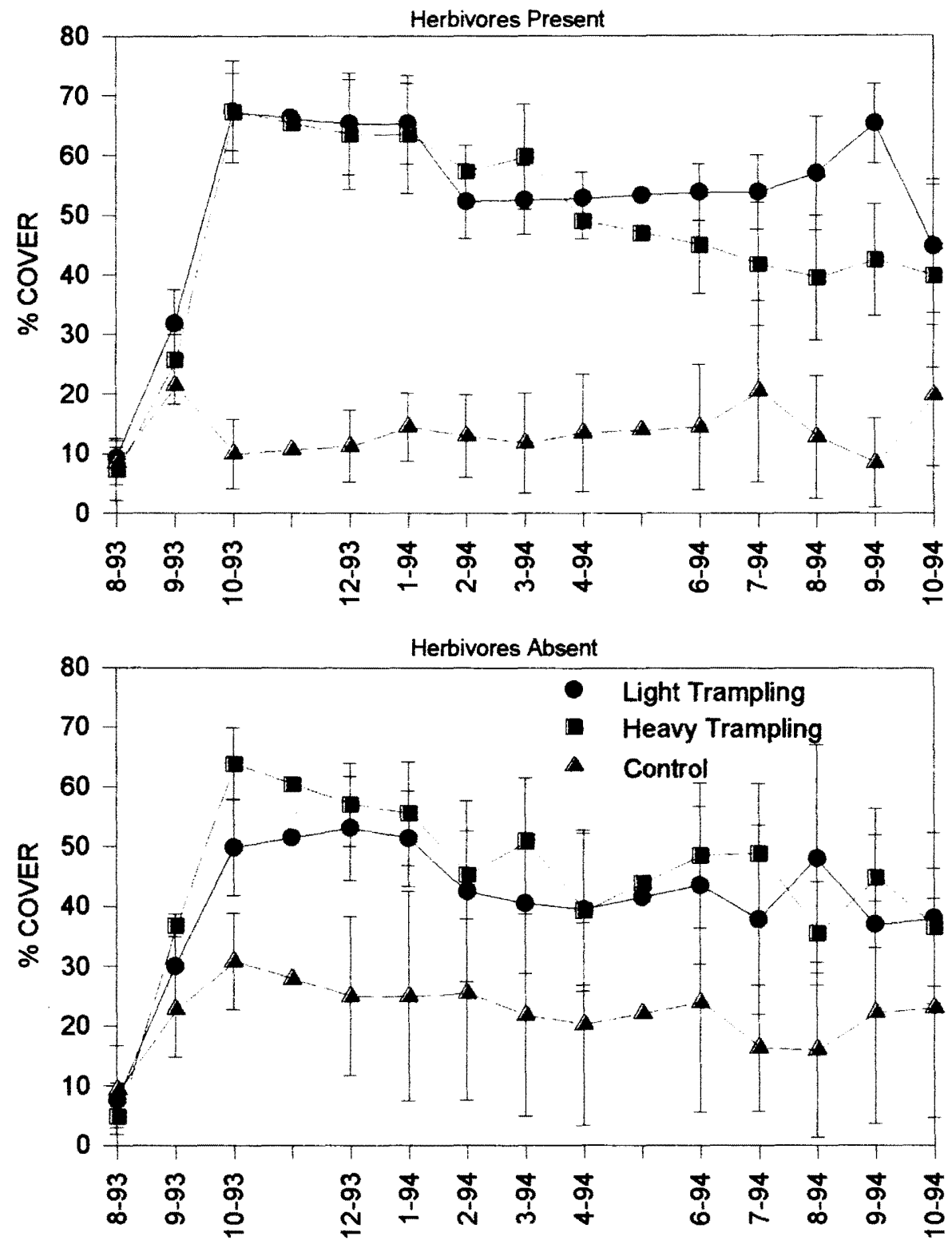
Figure 16. Recovery of Chthamalus dalli at Yaquina Head in the presence and absence of herbivores. Data points represent the mean, and vertical bars are $\pm 1 \mathrm{SE}$.
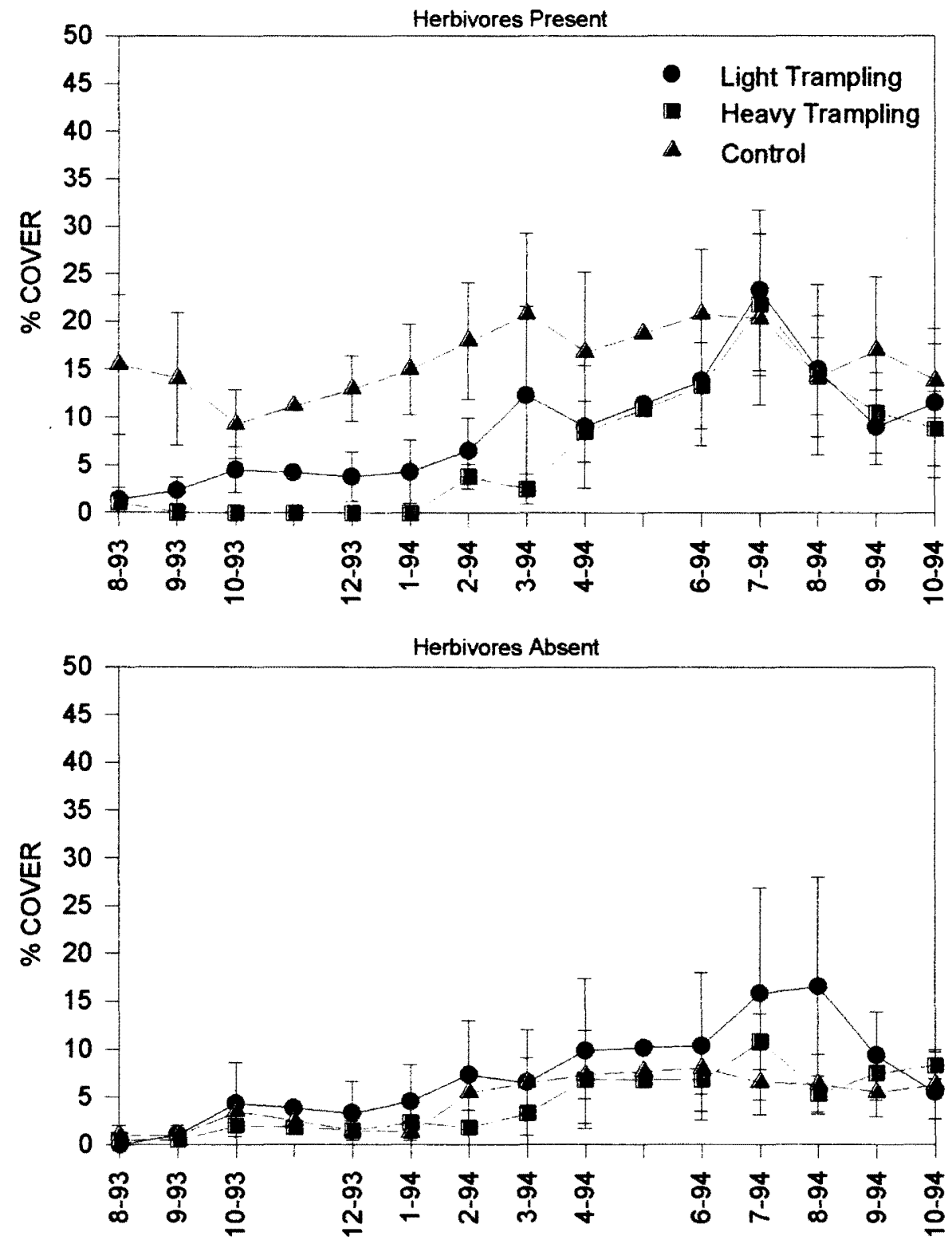
Table 9. Summary of RMANOVA on abundance of barnacles (Chthamalus dalli) in the recovery phase. Data were arcsine -transformed prior to analysis.

SOURCE

Between treatments

Site

Block\{site\}

Trampling\{site\}

Herbivore\{site\}

Trampling*Herbivore

Error

\section{Within treatments}

\begin{tabular}{lllll}
\hline Date & 12 & 0.438 & 37.824 & $\mathrm{P}<0.05$ \\
Date*Site & 12 & 0.219 & 18.866 & $\mathrm{P}<0.05$ \\
Date*Block\{site\} & 72 & 0.036 & 3.114 & $\mathrm{P}<0.05$ \\
Date*Trampling\{site\} & 48 & 0.068 & 5.895 & $\mathrm{P}<0.05$ \\
Date*Herbivore\{site\} & 48 & 0.013 & 1.104 & 0.335 \\
Date^Trampling*Herbivore & 48 & 0.012 & 1.057 & 0.392 \\
Error & 624 & 0.012 & &
\end{tabular}

Greenhouse-Geisser Epsilon: 0.5335: Huyn-Feldt Episilon: 0.8387 


\section{Fucoid Algae}

\section{Canopy (Table 10; Figs 17 and 18)}

During the trampling phase the fucoid canopy was completely removed. The recovery of the canopy was retarded in trampled plots at both sites (Figs 17 and 18). By the conclusion of the recovery phase, mean canopy cover in trampled plots remained below $20 \%$. There continued to be no difference between light and heavy trampling plots (Table 10). There was also no effect of herbivores at either site.

At Fogarty Creek, mean canopy cover in the controls was significantly greater than in the trampling treatments from August 1993 to September 1994. Mean canopy cover in the controls declined initially in the recovery phase following the downward trend seen in the trampling phase. In herbivore present plots mean canopy cover increased rapidly early in the recovery phase and reached a peak of $31 \%$ on October 1993. Canopy then declined to January 1994 after which it increased gradually, reaching a second higher peak of $36.3 \%$ on July 1994 . After July 1994 mean canopy declined, reaching $23 \%$ by October 1994 . In herbivore exclusion plots, mean canopy cover declined. rapidly between the trampling phase $(22 \%)$ and the recovery phase $(8 \%)$. Canopy cover then increased slightly through the 
recovery phase and reached $15.8 \%$ by October 1994 , which was lower than pre-trampling cover.

At Yaquina Head, mean canopy cover in the controls was significantly greater than in the trampling treatments throughout the recovery phase (Table 10). Mean cover of the canopy increased steadily throughout the recovery phase reaching a peak by August 1994. In the herbivore present plots, the peak mean cover reached $100 \%$, while in the herbivore exclusion plots the peak mean cover of $55 \%$. The mean cover was significantly greater than the pre-experimental of November 1992. 
Figure 17. Recovery of Fucoid algae (Canopy) at Fogarty Creek in the presence and absence of herbivores. Data points represent the mean, and vertical bars are $\pm 1 \mathrm{SE}$.
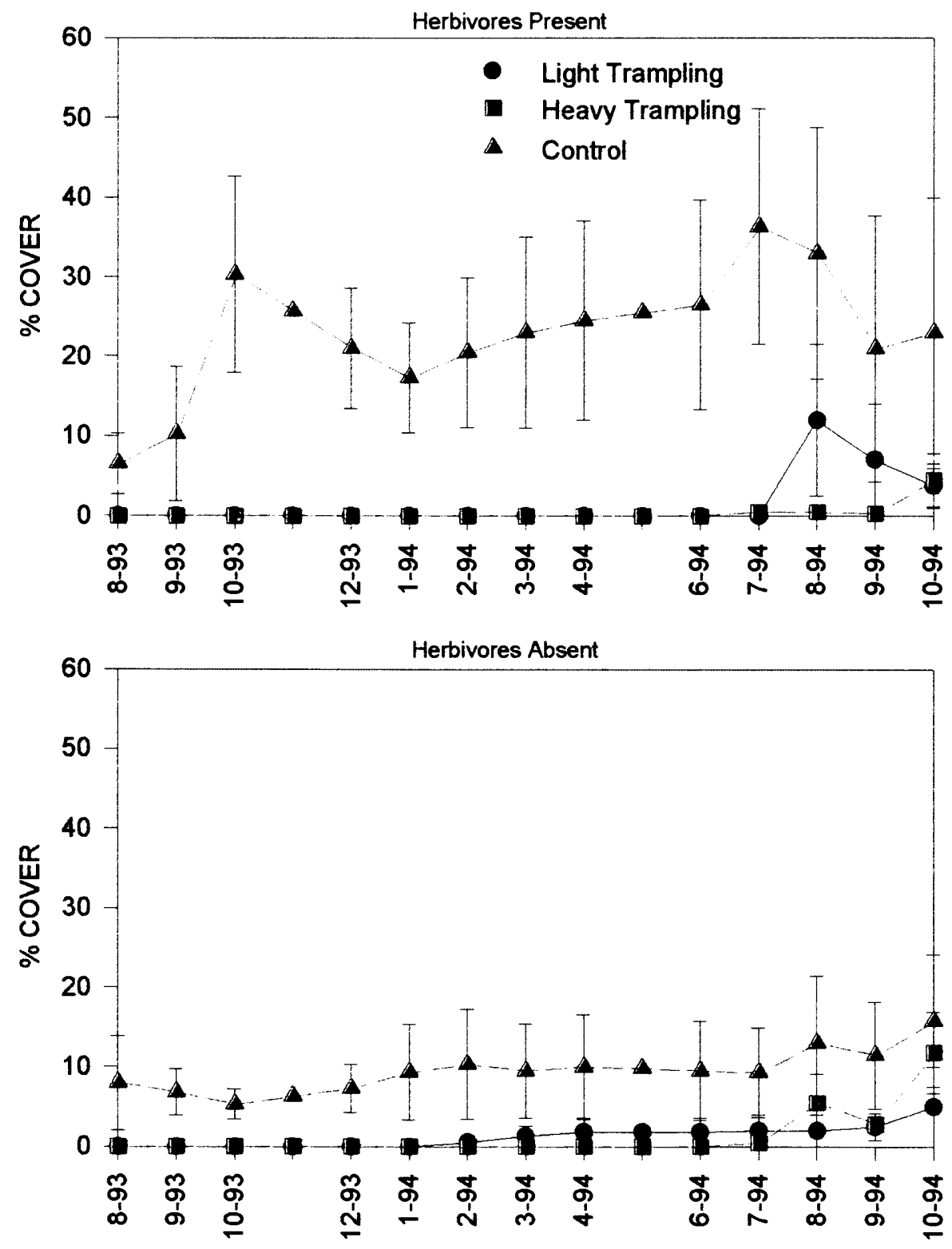
Figure 18. Recovery of Fucoid algae (Canopy) at Yaquina Head in the presence and absence of herbivores. Data points represent the mean, and vertical bars are $\pm 1 \mathrm{SE}$.
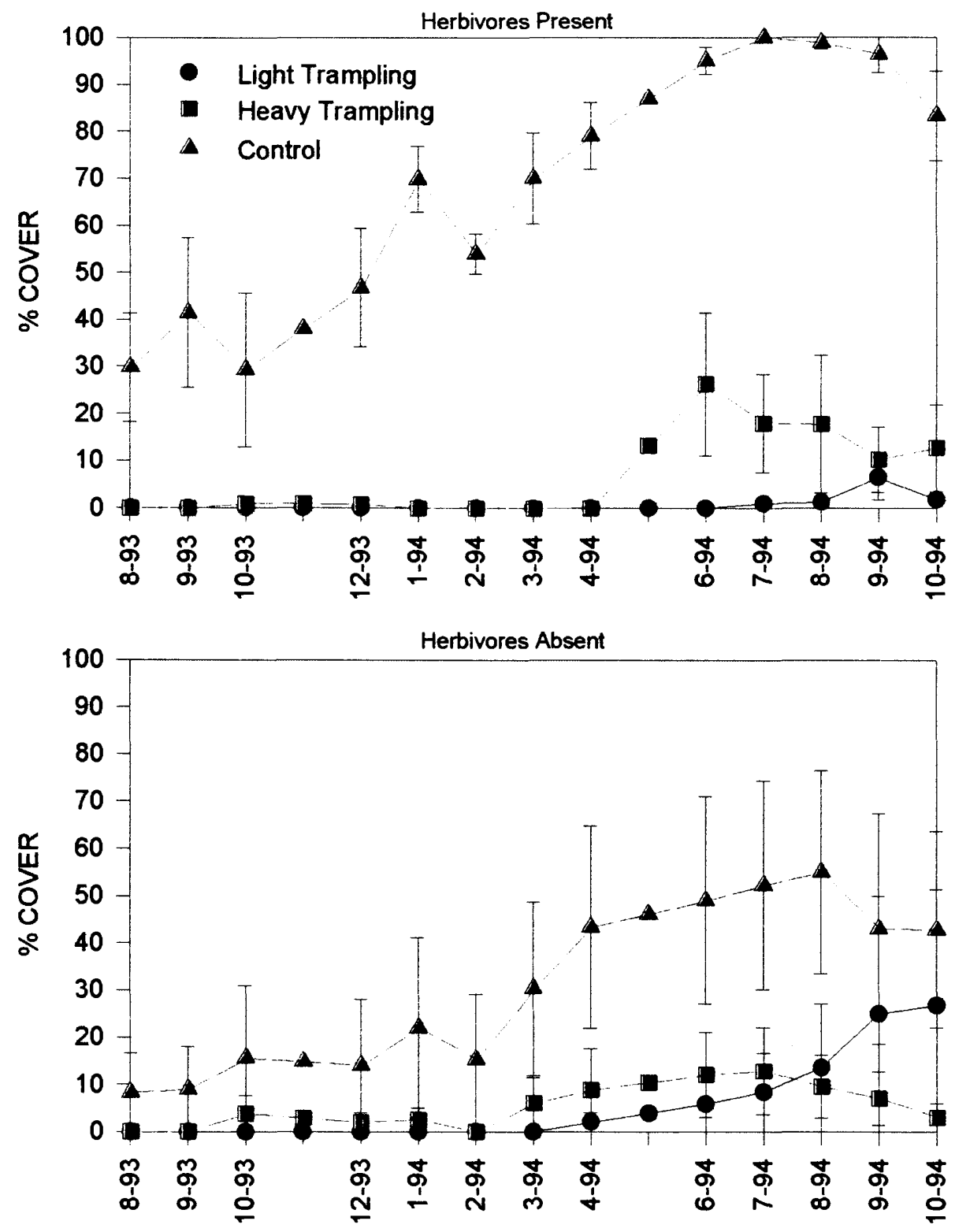
Table 10. Summary of RMANOVA on abundance of Fucoids (canopy) in the recovery phase. Data were arcsine -transformed prior to analysis.

\begin{tabular}{l}
\hline SOURCE \\
Between treatments \\
Site
\end{tabular}

Site

Block\{site\}

Trampling\{site\}

Herbivore\{site\}

Trampling*Herbivore

Error

\begin{tabular}{llll} 
DF & MS & F & $P$ \\
\hline
\end{tabular}

\section{Within treatments}

\begin{tabular}{lllll}
\hline Date & 12 & 0.865 & 39.748 & $\mathrm{P}<0.05$ \\
Date*Site & 12 & 0.366 & 16.810 & $\mathrm{P}<0.05$ \\
Date*Block\{site\} & 72 & 0.097 & 4.458 & $\mathrm{P}<0.05$ \\
Date*Trampling\{site\} & 48 & 0.148 & 6.804 & $\mathrm{P}<0.05$ \\
Date*Herbivore\{site\} & 48 & 0.015 & 0.688 & 0.946 \\
Date*Trampling*Herbivore & 48 & 0.017 & 0.797 & 0.835 \\
Error & 624 & 0.022 & &
\end{tabular}

Greenhouse-Geisser Epsilon: 0.6254: Huyn-Feldt Episilon: 0.9529 
Primary (Figs 19 and 20)

The mean cover of fucoid primary cover was too low for statistical analysis. At Fogarty Creek, primary cover was zero until after April 1994 at which point it never exceeded mean of $4 \%$. By the end of the recovery phase, mean cover was generally lower than the pretrampling levels of November 1992. Mean cover in control plots varied at Fogarty Creek, never exceeding $5 \%$. Mean cover remained higher than in the trampling plots except on the September 1994 in herbivore present plots, and June 1994 and July 1994 in herbivore exclusion plots.

At Yaquina Head, mean primary cover remained under $2 \%$ in herbivore present plots, while in herbivore exclusion plots mean primary cover remained under $4 \%$. In the controls in herbivore present plots, primary cover varied but continued on an upward trend that was observed in the trampling phase 
Figure 19. Recovery of Fucoid algae (Primary) at Fogarty Creek in the presence and absence of herbivores. Data points represent the mean, and vertical bars are $\pm 1 \mathrm{SE}$.
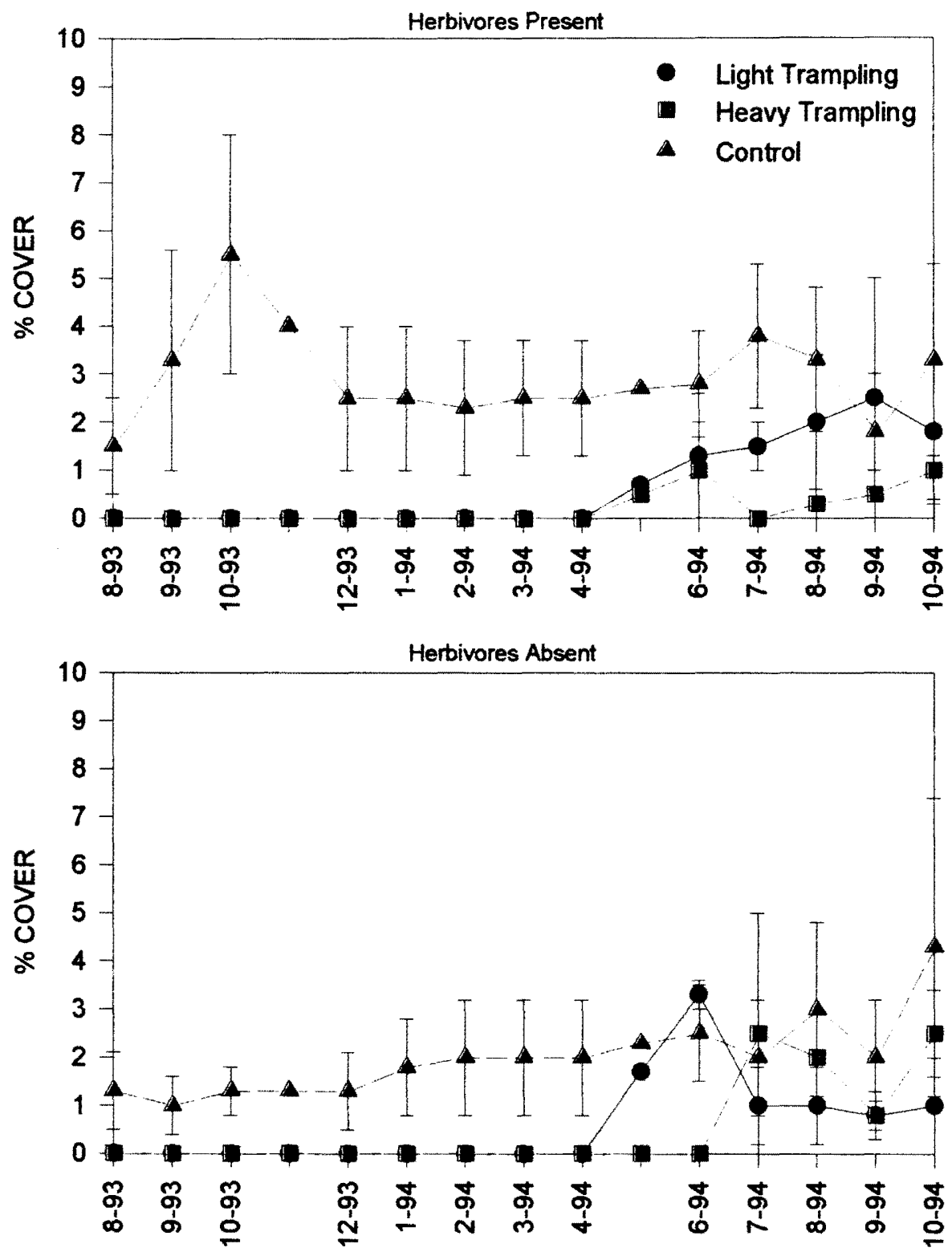
Figure 20. Recovery of Fucoid algae (Primary) at Yaquina Head in the presence and absence of herbivores. Data points represent the mean, and vertical bars are $\pm 1 \mathrm{SE}$.
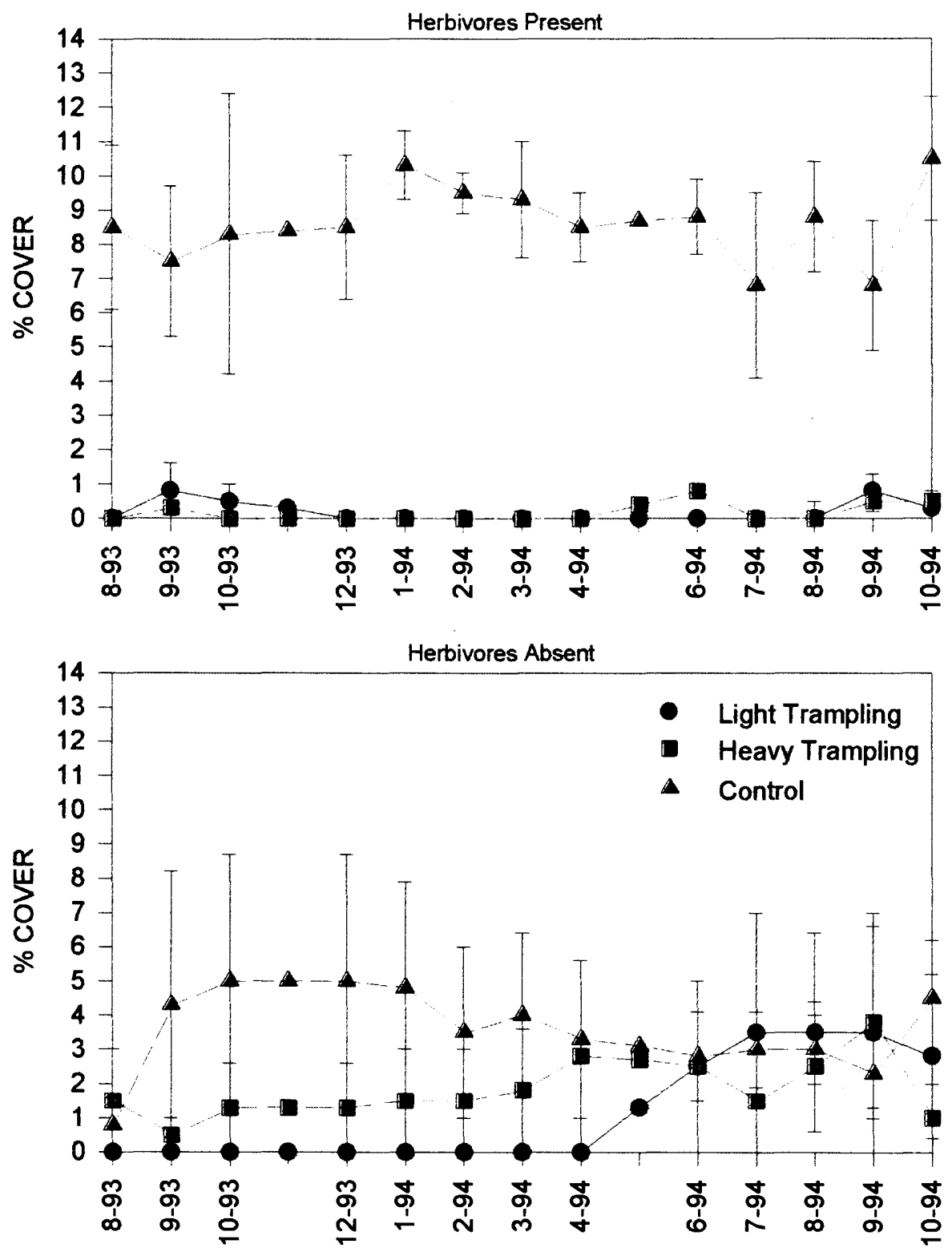
Endocladia muricata (Table 11; Fig 21)

In general mean, cover of $\underline{E}$. muricata increased throughout the recovery phase at Fogarty Creek (Fig 21). At Yaquina Head, E. muricata mean cover was very low throughout both the trampling phase and recovery phase and is not discussed in the this paper. The distribution of E. muricata was spatially heterogenic, within the site and blocks (Table 11). There was a peak in E. muricata cover at both sites between July 1994 and August 1994 (Fig 21). After this date E. muricata mean cover began to decline.

Mean cover of E. muricata in light and heavy trampling was significantly different than control on two dates. Mean cover of $\underline{E}$. muricata in heavy trampling was significantly different than the control on a further four dates. Mean cover of $\underline{E}$. muricata herbivore present treatments were significantly greater than herbivore exclusion on August 1993 (Table 11). 
Figure 21. Recovery of Endocladia muricata at Fogarty Creek in the presence and absence of herbivores. Data points represent the mean, and vertical bars are $\pm 1 \mathrm{SE}$.
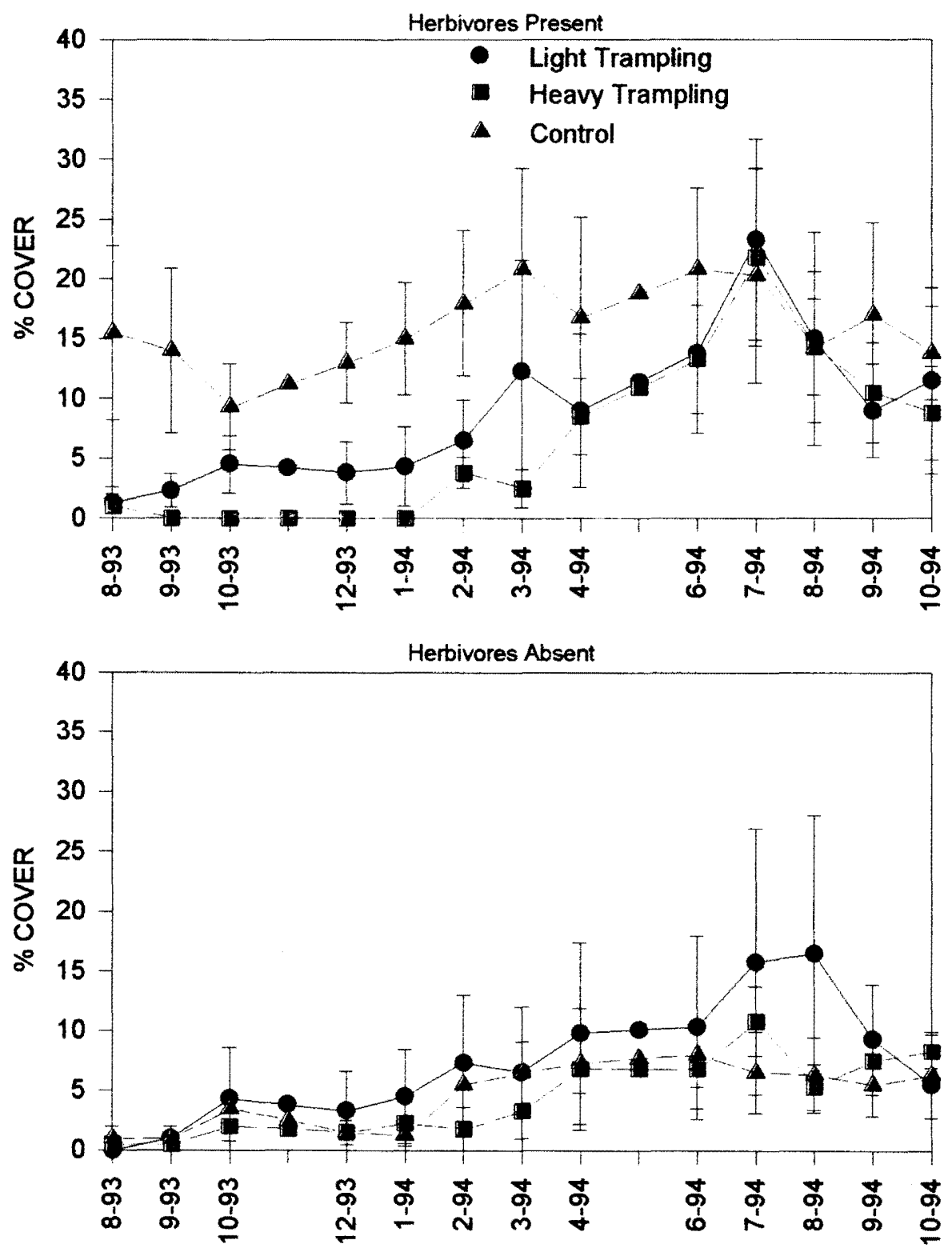
Table 11. Summary of RMANOVA on abundance of (Endocladia muricata) in the recovery phase. Data were arcsine -transformed prior to analysis.

\begin{tabular}{lllll}
\hline SOURCE & DF & MS & F & P \\
\hline Between treatments & & & & \\
Block & 3 & 1.187 & 8.600 & $\mathrm{P}<0.05$ \\
Trampling & 2 & 0.276 & 1.999 & 0.157 \\
Herbivore & 2 & 0.675 & 4.888 & 0.017 \\
Trampling*Herbivore & 4 & 0.228 & 1.649 & 0.195 \\
Error & 24 & 0.138 & &
\end{tabular}

Within treatments

\begin{tabular}{lllll}
\hline Date & 12 & 0.424 & 32.002 & $\mathrm{P}<0.05$ \\
Date*Block & 36 & 0.032 & 2.430 & $\mathrm{P}<0.05$ \\
Date*Trampling & 24 & 0.025 & 1.910 & $\mathrm{P}<0.05$ \\
Date*Herbivore & 24 & 0.023 & 1.746 & $\mathrm{P}<0.05$ \\
Date*Trampling*Herbivore & 48 & 0.009 & 0.665 & 0.956 \\
Error & 288 & 0.013 & &
\end{tabular}

Greenhouse-Geisser Epsilon: 0.3484: Huyn-Feldt Episilon: 0.6248 


\section{DISCUSSION}

The two phases of this study investigated a series of predictions on the effects of trampling, recovery from trampling and the presence or absence of herbivores on the upper shore barnacle-algal community (Tables 12 , and 13). Some of these predictions were supported, trampling dislodged the larger barnacle species, and the smaller, competitively inferior barnacle became more abundant in trampled plots. Fucoid algae were highly susceptible to trampling. Fucoid algae and $\underline{E}$. muricata recovered slowly in the absence of $\underline{B}$. glandula. Other predictions were not supported, herbivores had little effect on the ability of communities to persist or to recover under trampling conditions. There was no difference between the effects of light and heavy trampling on most species in the community. Overall, trampling changed the community from one dominated by $\underline{B}$. glandula and fucoid algae to one where the smaller barnacle $\underline{\mathrm{C}}$. dalli, algal crust, and bare space was more common. Succession was prevented because of direct effects of trampling on organisms and also because of indirect effects of the presence of barnacles. Balanus glandula recovery was slow due to low recruitment and competitive exclusion by $\underline{\mathrm{C}}$. dalli. Recruitment of $\underline{\mathrm{C}}$. dalli was high and individuals grew to a large size. 
Table 12. Predictions/Results during the Trampling Phase

\begin{tabular}{|c|c|c|}
\hline & HERBIVORES PRESENT & HERBIVORE EXCLUSION \\
\hline $\begin{array}{l}\text { No TRAMPLING } \\
\text { (CONTROL) }\end{array}$ & $\begin{array}{l}\text { Predicted: } \underline{\text { B. glandula }} \\
\text { abundant; } \text { C. dalli present at } \\
\text { low density; Late } \\
\text { successional algae abundant; } \\
\text { herbivore resistant species } \\
\text { present. Observed: } \\
\text { supported, however algae } \\
\text { were uncommon at Yaquina } \\
\text { Head. }\end{array}$ & 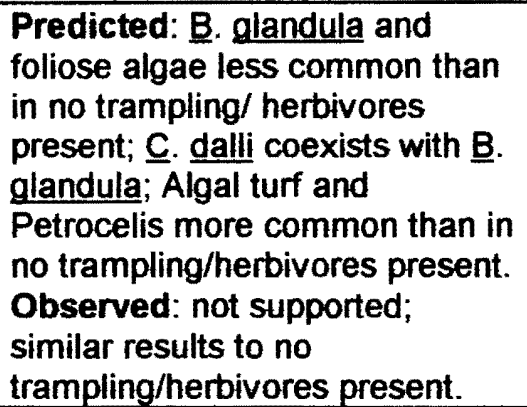 \\
\hline $\begin{array}{l}\text { LIGHT } \\
\text { TRAMPLING }\end{array}$ & $\begin{array}{l}\text { Predicted: Reduction in } \\
\text { biomass; no large changes in } \\
\text { community composition; } \underline{B} \text {. } \\
\text { glandula less common; } \underline{\mathrm{C}} \text {. } \\
\text { dalli more common; algal turf } \\
\text { and grazer-resistant species } \\
\text { more common; algal canopy } \\
\text { present but lower than } \\
\text { controls. } \\
\text { Observed: not supported; } \underline{B} \text {. } \\
\text { glandula and fucoid algae } \\
\text { reduced to near zero levels; } \\
\text { increased C. dalli cover. }\end{array}$ & $\begin{array}{l}\text { Predicted: B. glandula and } \\
\text { fucoid algae more common than } \\
\text { light trampling/herbivore present; } \\
\text { C. dalli less common; algal } \\
\text { canopy less abundant than in } \\
\text { controls. Observed: not } \\
\text { supported; } \text { B. glandula and } \\
\text { fucoid algae reduced to near } \\
\text { zero levels; increased } \underline{\text { C. dalli }} \\
\text { cover. }\end{array}$ \\
\hline $\begin{array}{l}\text { HEAVY } \\
\text { TRAMPLING }\end{array}$ & $\begin{array}{l}\text { Predicted: } \underline{\text { B. glandula }} \\
\text { significantly reduced; } \underline{\text { C. dalli }} \\
\text { more abundant; fucoid algae } \\
\text { decrease; algal turf and } \\
\text { petrocelis more. } \\
\text { Observed: supported; } \\
\text { reduction in } \underline{\text { B. glandula; }} \\
\text { increase in } \underline{\mathrm{C}} \text {. dalli; foliose } \\
\text { algae removed; petrocelis } \\
\text { and bare rock more } \\
\text { abundant. }\end{array}$ & $\begin{array}{l}\text { Predicted: } \underline{B} \text {. glandula } \\
\text { abundance low; fucoid algae } \\
\text { abundance low; } \underline{\text {. dalli more }} \\
\text { common and coexist with } \mathrm{B} \text {. } \\
\text { glandula; species dominant in no } \\
\text { trampling will persist. } \\
\text { Observed: } \underline{B} \text {. glandula persist } \\
\text { longer; trampling swamped } \\
\text { herbivore effects - no difference } \\
\text { between herbivore inclusion and } \\
\text { exclusion plots. }\end{array}$ \\
\hline
\end{tabular}


Table 13. Predictions/Results during Recovery Phase.

\begin{tabular}{|c|c|}
\hline & HERBIVORES PRESENT AND HERBIVORE EXCLUSION \\
\hline $\begin{array}{l}\text { No TRAMPLING } \\
\text { (CONTROL) }\end{array}$ & $\begin{array}{l}\text { Predicted: } \mathrm{B} \text {. glandula abundant; } \underline{\mathrm{C}} \text {. dalli present at low density; } \\
\text { Late successional algae abundant. } \\
\text { Observed: supported, however algae were uncommon at } \\
\text { Yaquina Head. C. dalli abundance increased due to high } \\
\text { recruitment. }\end{array}$ \\
\hline $\begin{array}{l}\text { LIGHT AND } \\
\text { HEAVY } \\
\text { TRAMPLING }\end{array}$ & 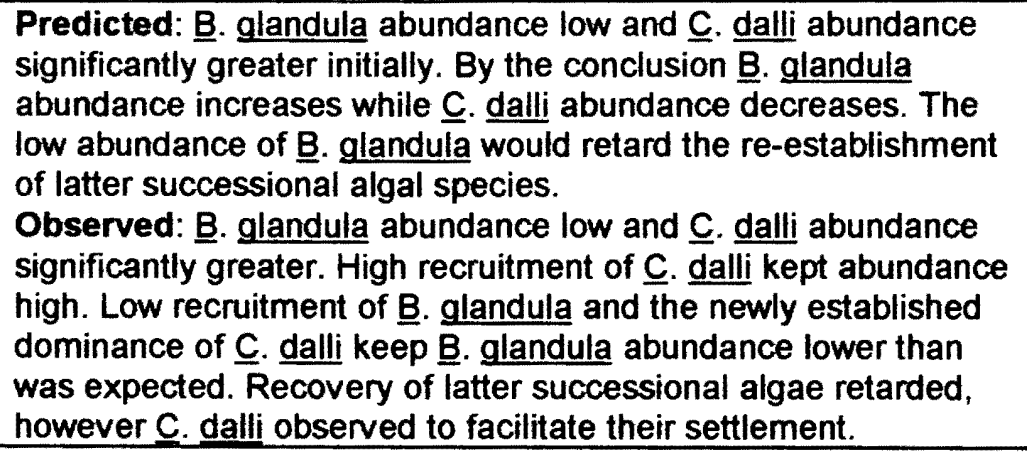 \\
\hline
\end{tabular}

\section{Trampling Intensity}

It was predicted that light and heavy trampling would have different effects on the community. For instance, it was predicted that $\underline{B}$. glandula and fucoid algae would be reduced but not removed in lightly trampled plots. These predictions were not supported, as there was no difference between light and heavy trampling in any of the experimental plots. Clearly the definition of light trampling was not "biologically light", as both light and heavy trampling had the same effect on the community. These intensities were chosen based on what was considered to be realistic light and heavy 
trampling regimes. Brosnan and Crumrine $(1992 a, b)$ found that at rarelyvisited and relatively inaccessible sites on the Oregon coast, trampling ranged from 7-10 steps per hour. Organisms at two marine gardens (=reserves) were trampled 228 times per hour at one site, and 103 times per hour at the second. Povey and Keough (1991) found that algal species were much reduced by light and heavy trampling, but that heavy trampling caused a greater reduction. In their study, trampling was carried out daily for four months. Light trampling was defined as trampling twice per day, and intense trampling was 25 times per day. We did not trample daily, as most trampling occurs during low tide periods, and thus many species are not trampled every day. Nonetheless, light trampling had severe effects on the community. This is alarming, as it implies that in this community, trampling is a threshold phenomenon, and that the threshold for effects may be low. This will have important consequences for conservation of intertidal communities. It implies that simply reducing the numbers of visitors on a shore to moderate levels will not be sufficient to maintain species composition and abundance. This will need to be taken into account when decisions are made to increase access to intertidal zones, and to designate intertidal marine reserves. 
Interactions between trampling and herbivore effects It was predicted that trampling and grazing would have additive effects on species abundance. This prediction was supported only for $\underline{B}$. glandula at Yaquina Head in the trampling phase. Herbivores decreased recruitment and increased the rate of loss of new barnacles in trampled plots. New recruits were susceptible to bulldozing before they were large enough to be dislodged by trampling. Barnacles that escaped bulldozing were subsequently dislodged by trampling. A corollary prediction was that under light trampling, and in the absence of grazers, $\underline{\text { B. glandula and algae }}$ would be able to establish itself. This prediction was not supported. The effects of trampling were intense enough to swamp any herbivore effect. In trampled plots, abundance of algae and B. glandula was the same in herbivore inclusion and herbivore exclusion treatments. There was no correlation between effects of trampling and abundance of herbivores, indicating that herbivore effects did not depend on the intensity of trampling. These results imply that communities do not recover while trampling is ongoing. Even when the detrimental effect of limpets was removed, barnacles and algae did not reestablish themselves successfully. 


\section{Effects of Trampling on Barnacles}

It was predicted that $\underline{B}$. glandula would be removed by trampling, and that the smaller $\underline{C}$. dalli would be resistant to dislodgment. These predictions were supported. The abundance of $\underline{\mathrm{C}}$. dalli increased in trampled plots.

Trampling removed $\underline{B}$. glandula and created bare space which was subsequently colonized by $\underline{\mathrm{C}}$. dalli. At Fogarty Creek, cover of $\underline{\mathrm{C}}$. dalli increased from $0 \%$ to $40 \%$ in some plots over the nine month experimental period. During the same time $\underline{\text { B. }}$ glandula declined. Thus, trampling prevents competitive exclusion of $\underline{\mathrm{C}}$. dalli by $\underline{B}$. glandula. Once $\underline{\mathrm{C}}$. dalli establish they may persist for some time. Farrell (1989) found that at Yaquina Head, it took

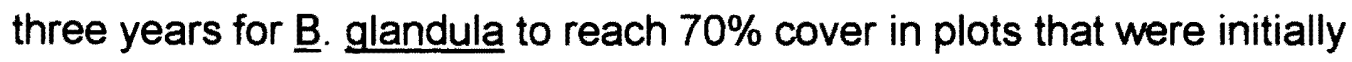
dominated by $\underline{\mathrm{C}}$. dalli. Dominance by $\underline{\mathrm{C}}$. dalli can slow the rate of succession and recovery in this community (Farrell 1989, 1991, and see below).

Size and profile of barnacles determine their susceptibility to trampling. B. glandula is a large barnacle with a high profile, and is easily dislodged by trampling. Young and newly settled individuals are smaller and flat, and are not as vulnerable to trampling. However, as they grow their risk of dislodgment increases. For instance, barnacle cover gradually declined in trampled plots following the settlement pulse in March 1993. Hummocking also increases susceptibility to dislodgment. At Yaquina Head, B. glandula was abundant and settlement was high. Clumps of hummocked barnacles 
were common at this site, and I found that they were easily removed by walking on them.

\section{Effect of Trampling on Algae}

As predicted, fucoid algae were susceptible to trampling, and cover dropped to near zero in many plots. This confirms the results of previous studies (Zedler 1976, 1978, Beauchamp and Gowing 1982, Povey and Keough 1991, Brosnan and Crumrine 1992a 1994, Brosnan 1993). Fucoid species are often attached at a single point and dislodgment at the point of attachment results in a large canopy loss (Brosnan and Crumrine 1994). Many fucoids are attached to barnacles (Farrell 1991; Grubba and Brosnan personal observation); by removing barnacles, trampling indirectly removes algae. When this happens, primary cover is also lost, and plants cannot regenerate from holdfasts.

E. muricata was removed by trampling. This was partly due to the settlement and growth patterns of E. muricata in the experimental plots. Most plants were growing as epibionts on the sides of barnacles. When barnacles were dislodged, the epibionts were lost too. The epibiont E. muricata often grows in upright clumps on mussels and barnacles (Brosnan and Crumrine 1994, Grubba personal observation). In this form, E. muricata is easily removed by trampling (Brosnan and Crumrine 1994). However, when $\underline{E}$. 
muricata grows as a prostrate, spreading turf, it is not easily dislodged by foot traffic (Brosnan and Crumrine 1992a, 1994). Endocladia muricata abundance increased in the presence of herbivores in control plots. This is despite the fact that barnacles (settlement substrate) were removed by herbivores. This effect has been previously noted by Brosnan (unpublished manuscript), but its causes are unknown.

\section{Spatial Heterogeneity}

Crevices in rocks are important spatial escapes from trampling. I did not document whether species were found in crevices or on horizontal surfaces. However, it was noted that species that are removed by trampling sometimes persisted in crevices (Grubba and Brosnan personal observation). This was true for $\underline{B}$. glandula, fucoids, and $\underline{E}$. muricata (on barnacles). In fact in trampled plots almost all of these individuals were found in depressions in the rock. If the crevices were small, they provided only temporary refuge. For instance, B. glandula grew out of small crevices and were subsequently dislodged by trampling. However, barnacles and algae persisted in larger crevices (Grubba and Brosnan personal observation). The presence of spatial refuges may be important to persistence of these species in highly disturbed shores. Refuges prevent local extinction of species, and individuals in refuges are a potential source 
of new recruits. Thus, recovery from trampling is likely to be faster on shores with high heterogeneity. By contrast, in areas where the rock surface is smooth (e.g., sandstone and metamorphosed sandstone) recovery may be slower.

\section{Effect of trampling on successional pathway}

By removing key species in the successional pathway, trampling can prevent succession. The barnacle $\underline{B}$. glandula is essential to succession because it facilitates algae and mussels (Farrell 1989, 1991, D. M. Brosnan unpublished manuscript). Chthamalus dalli, if abundant and large in size can facilitate settlement of algae and mussels. However $\underline{C}$. dalli even when large, are not as effective as $\underline{B}$. glandula at facilitation. In other geographic areas barnacles are also key species in succession (e.g., Hawkins 1981, 1983, Hawkins and Hartnoll 1983, Hartnoll and Hawkins 1985). On temperate shores, disturbances often remove algae and invertebrates, and create patches of bare space (Harger 1970, Sousa 1979, 1984, Hartnoll and Hawkins 1985, Paine and Levin 1981, Farrell 1989). On some shores, this space is colonized by barnacles that facilitate succession to algae or mussels (Paine and Levin 1981, Hawkins and Hartnoll 1983, Farrell 1989, 1991). Trampling also removes organisms and creates patches of bare space (Brosnan and Crumrine 1994). However, $\underline{B}$. glandula is removed by 
trampling, and does not recover while trampling continues. Many algal species depend on B. glandula for recruitment, and in the presence of trampling these species cannot recruit. This is true for species such as the turf form of E. muricata, which requires $\underline{B}$. glandula in order to become established (Farrell 1991, Brosnan unpublished manuscript). Once it has spread to primary substrate, it is resistant to trampling and can thrive in trampled conditions (Brosnan and Crumrine 1992a, 1994). In addition, mussel recruitment is enhanced by barnacles (Navarette and Castilla 1990, Brosnan unpublished). Thus one effect of trampling on the community is to retard or prevent succession. This interpretation is supported by the observation that algae in trampled plots were only found on $\underline{B}$. glandula in crevices.

Once trampling has stopped succession may be slow. This is because $\underline{\underline{C}}$. dalli becomes more abundant when the larger competitively dominant $\underline{B}$. glandula is dislodged. Chthamalus dalli does not usually enhance succession (Farrell 1989, 1991) because it is too small and smooth for algae to recruit successfully. However to recruit successfully under the right conditions $\underline{\mathrm{C}}$. dalli can grow to large sizes that enable algae to recruit successfully. Under these conditions succession /recovery of the community may not be as retarded. It may take three years for $\underline{B}$. glandula to replace

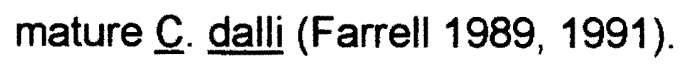




\section{CONCLUSIONS}

Trampling alters the community in the upper intertidal zone of rocky shores. Species composition changes from one that is dominated by the barnacle $\underline{B}$. glandula or by a mixed $\underline{B}$. glandula and algae assemblage, to a community where $\underline{\underline{C}}$. dalli is the most abundant barnacle, and algal crust is practically the only algal species present. Recovery of impacted communities is dependent on the presence of $\underline{B}$. glandula, a keystone species in succession. Studies suggest that full recovery of an impacted community would take a minimum of three years.

Park and reserve managers will have to modify their management plans incorporating the ideas that 'light' trampling, has as detrimental effect as "heavy" trampling, recovery is a lengthy process, and for recovery there has to be a removal of impacts such as trampling. This presents the challenge of balancing the conservation of these areas with the everincreasing visitation by humans, which is only going to increase in the future. 


\section{REFERENCES}

Bates, G. H. 1934. The relation of leaf size to root structure in

Trifolium repens. Journal of Ecology 22:271-278.

_ 1935. The vegetation of footpaths, sidewalks, cart-tracks and gateways. Journal of Ecology 23:470-487.

Beauchamp, K. A. and M. M. Gowing. 1982. A quantitative assessment of human trampling effects on a rocky intertidal community. Marine Environmental Research 7:279-283.

Boalche, G. T., N. A. Holme, N.A. Jephson and J.m. Sidwell. 1974. A resurvey of Colemans intertidal traverse at Wembury, South Devon. Journal of Marine Biology Association of the United Kingdom 54:551553.

Branch, G. M. 1975. Ecology of Patella species from the Cape Peninsula, South Africa. IV Desiccation. Marine Biology 32:179-200. _ 1981. The biology of limpets: physical factors, energy flow and ecological interactions. Oceanography and Marine Biological Annual Review 19:235-379. 
Brosnan, D. M. 1993. The effect of human trampling on biodiversity of rocky shores: monitoring and management strategies. Recent Advances in Marine Science and Technology 1992:333-341.

Brosnan, D. M. and L. C. Crumrine. 1992a. Human impact and a management strategy for Yaquina Head Outstanding Natural Area. A report to the Bureau of Land Management Dept of the Interior, Salem, Oregon, $105 \mathrm{pp}$.

_. 1992b. A study of human impact on four shores on the Oregon coast: Results and recommendations for management and development. Report to the Oregon State Department of Land Conservation and Development, $36 \mathrm{pp}$.

_ 1994. Effects of human trampling on marine rocky shore communities. Journal of Experimental Biology and Ecology in press.

Burden, R. F. and P. F. Randerson. 1972. Quantitative studies of the effects of human trampling on vegetation as an aid to the management of semi-natural areas. Journal of Applied Ecology 9:439-458.

Burrows, E. M., and S. M. Lodge. 1950. A note on the interrelationships of Patella, $\underline{\text { Balanus }}$ and Fucus on a semi-exposed coast. Annual Report for 1949, Marine Biology Station, Port Erin 62:30-34.

Castilla, J. C. and R. H. Bustamente. 1989. Human exclusion from rocky intertidal of Las Cruces, central Chile: effects on Durvillea 
antarctica (Phacophyta, Durvilleales). Marine Ecology Progress Series 50:203-214.

Castilla, J. C. and L. R. Duran. 1985. Human exclusion from the rocky intertidal zone of central Chile: the effects on Concholepis concholepis (Gastropoda). Oikos 45:391-399.

Connell, J. H. 1961. The influence of interspecific competition and other factors on the distribution of the barnacle Chthamalus stellatus. Ecology 42:710-723.

Cubit, J. D. 1984. Herbivory and the seasonal abundance of algae on a high rocky intertidal shore. Ecology 65:1904-1917.

Duran, L. R. and J. C. Castilla. 1989. Variation and persistence of the middle rocky intertidal community of central Chile, with and without human harvesting. Marine Biology 103:555-562.

Farrell, T. M. 1989. Succession in a rocky intertidal community: the importance of disturbance size and position within a disturbed patch. Journal of Experimental Marine Biology and Ecology. 128:57-73.

_ 1991. Models and mechanisms of succession: an example from a rocky intertidal community. Ecological Monographs 61:95-113.

Ghazanshahi, J., T. D. Huchel and J. S. Devinney. 1983. Alteration of Southern California rocky shore ecosystems by public and recreational use. Journal of Environmental Management 16:379-394. 
Godoy, C. and C. A. Moreno. 1989. Indirect effects of human exclusion from the rocky intertidal in southern Chile: a case of crosslinkage between herbivore. Oikos 54:101-106.

Harger, J. R. E. 1970. The effect of wave impact on some aspects of the biology of mussels. Veliger 12:401-414.

Hartnoll, R. G., and S. J. Hawkins (1985). Patchiness and fluctuations on a moderately exposed shore. Ophelia 24:53-63.

Hawkins, S. J. 1981. The influence of season and barnacles on the algal colonization of Patella vulgata exclusion areas. Journal of the Marine Biological Association of the United Kingdom 61:1-15.

_. 1983. Interactions of Patella and macroalgae with settling Semibalanus balanoides (L.). Journal of Experimental Marine Biology and Ecology 71:55-72.

Hawkins, S. J., and R. G. Hartnoll. 1983. Grazing of intertidal algae by marine invertebrates. Oceanography and Marine Biology Annual Review 21:195-282.

Hockey P. A. R., and A. Bosman. 1986. Man as an intertidal predator in Transkei: disturbance, community convergence and management of a natural food resource. Oikos 46:3-14. 
Hylgaard, T. and M. J. Liddle. 1981. The effect of human trampling on a sand dune ecosystem dominated by Empetrum nigrum. Journal of Applied Ecology 18:559-569.

Jeffreys, H. 1917. On the vegetation of four Durham Coal Measure fells, III and IV. Journal of Ecology 5:129-154.

Jernakoff, P. 1983. Factors affecting the recruitment of algae in a midshore region dominated by barnacles. Journal of Experimental Marine Biology and Ecology 67:17-31.

Kay, A. M. and M. J. Liddle. 1989. Impact of human trampling in different zones of a coral reef. Environmental Management 13:509-520.

Kozloff, E. 1973. Seashore Life of the Northern Pacific Coast. University of Washington Press Seattle.

Lewis, J. R. 1964. The ecology of rocky shores. English University Press UK.

Liddle, M. J. 1975. A selective review of the ecological effects of human trampling on natural ecosystems. Biological Conservation 7:1736.

_. 1991. Recreation Ecology: Effects of trampling on plants and corals. Trends in Ecology and Evolution 6:13-16. 
Liddle, M. J. and M. M. Kay. 1987. Resistance, survival and recovery of trampled corals on the Great Barrier Reef. Biological Conservation 42:1-18.

Lubchenco, J. 1978. Plant species diversity in a marine intertidal community: importance of herbivore food preference and algal competitive abilities. American Naturalist 112:23-39.

_. 1983. Littorina and Fucus: effects of herbivores, substratum heterogeneity, and plant escapes during succession. Ecology 64:11161123.

Moreno, C. A., J. P. Sutherland and F.H. Jara. 1984. Man as a predator in the intertidal zone of central Chile. Oikos 42:155-160.

Navarrete, S. A., and J. C. Castilla. 1990. Barnacle walls as mediators of intertidal mussel recruitment: effects of patch size on the utilization of space. Marine Ecology - Progress Series 68:113-119.

Nickerson, N. H. and F. R. Thibodeau. 1983. Destruction of Ammophila breviligulata by pedestrian traffic: quantification and control. Biological Conservation 27:277-287.

Olivia, D. and J. C. Castilla. 1986. The effects of human exclusion on the population structure of key-hole limpets Fisurella crassa and $\underline{F}$. limbata on the coast of central Chile. PSZNI Marine Ecology 7:201-217. 
Osenberg, C. W.and R. J. Schmitt. 1994. Detecting human impacts in marine habitats. Ecological Monographs 4:1-2.

Osenberg, C. W., R. J. Schmitt, S. J. Holbrook, K. E. Abu-Saba, and A. R. Flegal. 1994. Detection of environmental impacts: natural variability, effect size and power analysis.Ecological Monographs 4:1631.

Paine, R. T., and S. A. Levin. 1981. Intertidal landscapes: disturbance and the dynamics of pattern. Ecological Monographs 51:145-178.

Petersen, J. H. 1984a. Larval settlement behavior in competing species: Mytilus californianus Conrad and $\underline{M}$. edulis L. Journal of Experimental Marine Biology and Ecology 82:147-159

Povey, A. and M. J. Keough. 1991. Effects of trampling on plant and animal populations on rocky shores. Oikos 61:355-368.

Shantz, H. L. 1917. Plant succession on abandoned roads in eastern Colorado. Journal of Ecology 5:19-34.

Sokal, R. R. and F. J. Rohlf. 1981. Biometry. W.H. Freeman and Co,. New York, second edition, 859 pp.

Sousa, W. P. 1979. Experimental investigations of disturbance and ecological succession in a rocky intertidal algal community. Ecological monographs 49:227-254. 
1984. Intertidal mosaics: patch size, propagule availability and spatially variable patterns of succession. Ecology 65:1918-1935.

Stephenson, T. A., and A. Stephenson. 1972. Life between tidemarks on rocky shores. W. H. Freeman and Co.San Francisco, USA.

Sun, D. , and M. J. Liddle. 1993. A survey of trampling effects on vegetation and soil in eight tropical and subtropical sites. Environmental management. 17:495-510.

Thom, R. M. and T. B. Widdowson. 1978. A resurvey of E. Yale Dawson's ' 42 intertidal algal transects on the southern California mainland after 15 years. Bulletin of Southern Californian Academy of Science 77:1-13.

Thrush, S. F., R. D. Pridmore, and J. E. Hewitt. 1994. Impacts on softsediment macrofauna, the effects of spatial variation on temporal trends. Ecological Monographs 4:31-42.

Underwood, A. J. 1980. The effects of grazing by gastropods and physical factors on the upper limits of distributions of intertidal macroalgae. Oecologia (Berlin) 46: 201-213.

Underwood, A. J. and S. J. Kennelly. 1990. Pilot studies for designs of surveys of human disturbance of intertidal habitats in New South Wales. Australian Journal of Marine and Freshwater Research 41:165173. 
Widdowson, T. B. 1971. Changes in the intertidal algal flora of the L. A. since the survey of E. Yale Dawson in 1956-1959.,Bulletin of Southern Californian Academy of Science 70:2-16.

Zedler, J. B. 1976. Ecological resource inventory of the Cabrillo National Monument intertidal zone. Project Report of the U.S. Dept. of Interior National Park Service. 69 pp.

_ 1978. Public use effects in the Cabrillo National Monument intertidal zone. Project Report of the U.S. Dept. of Interior National Park Service. 52 pp. 